\title{
Annual Report on External Quality Assessment Scheme for Clinical Microbiology in Korea (2014)
}

Young Jin $\mathrm{Ko}^{1}$, Mi-Na Kim${ }^{1}$, Eui Chong $\mathrm{Kim}^{2}$, Jong Hee Shin $^{3}$, Nam Yong Lee', Sunjoo $\mathrm{Kim}^{5}$, Seok Hoon Jeong, JaeSeok Kim ${ }^{7}$, Chang Ki Kim ${ }^{8}$, Hye Gyung Bae, Nam Surp Yoon $^{1}$, Se Ik Joo ${ }^{2}$, Yu Yeon Hwang $^{4}$, Keonhan Kim ${ }^{6}$, In $\mathrm{Ho} \mathrm{Jang}^{10}$, and Jin $\mathrm{Heo}^{11}$, as Clinical Microbiology Subcommittee, Korean Association of External Quality Assessment Service

${ }^{1}$ Department of Laboratory Medicine, University of Ulsan and Asan Medical Center, Seoul; ${ }^{2}$ Department of Laboratory Medicine, Seoul National University Hospital, Seoul; ${ }^{3}$ Department of Laboratory Medicine, Chonnam National University Hospital, Gwangju; ${ }^{4}$ Department of Laboratory Medicine and Genetics, Samsung Medical Center, Sungkyunkwan University School of Medicine, Seoul; ${ }^{5}$ Department of Laboratory Medicine, Kyungsang National University Hospital, Jinju; ${ }^{6}$ Department of Laboratory Medicine, Gangnam Severance Hospital, Yonsei University College of Medicine, Seoul; ; Department of Laboratory Medicine, Kangdong Sacred Heart Hospital, Hallym University College of Medicine, Seoul; ${ }^{8}$ Department of Laboratory Medicine, Korean Institute of Tuberculosis, Cheongju:

${ }^{9}$ Department of Laboratory Medicine, Greencross Reference Laboratory, Yongin; ${ }^{10}$ Department of Laboratory Medicine, Wonju Severance Christian Hospital, Wonju; ${ }^{11}$ Department of Laboratory Medicine, Korea University Ansan Hospital, Ansan, Korea

Corresponding author: Mi-Na Kim

Department of Laboratory Medicine, Asan Medical Center, 88 Olympic-ro 43-gil, Songpa-gu, Seoul 05505, Korea

Tel: $+82-2-3010-4511$

Fax: +82-2-478-0884

E-mail:mnkim@amc.seoul.kr
Annual proficiency surveys were performed in March, June and September 2014 by clinical microbiology division of The Korean Association of Quality Assurance for Clinical Laboratory. Parasitology part has been newly incorporated in this survey. For each trial, three sets which were composed of different combinations of five bacteria and yeast were distributed for gram stain, culture, identification, and antimicrobial susceptibility tests of general bacteriology and five fixed sputum smear on slides were distributed for acid fast bacilli stain. Two advanced bacteriology survey materials for culture and identification of anaerobic bacteria and mold were distributed to the voluntary participants in every trial and five mycobacterial culture and identification specimens, five anti-tuberculosis susceptibility testing specimens, and two Mycobacterium tuberculosis strains for rapid detection of rifampin and isoniazid resistance were distributed to the voluntary participants in March and June trials. Five virtual microscopic slides for stool parasite examination were open for the registered participants in June trial. A total of 340 laboratories were enrolled and 330 (97.0\%), 331 (97.4\%), and 331 (97.4\%) returned the results on trial I, II, and III, respectively. For bacterial identification, the percent acceptable identification of Burkholderia cepacia, Klebsiella pneumoniae, Streptococcus pyogenes, Staphylococcus aureus, Pseudomonas aeruginosa, Streptococcus pneumoniae, Streptococcus agalactiae, Plesiomonas shigelloides, and Enterococcus faecalis were greater than 95\%. Group C and group D Salmonella species challenged as the different sets of M1422 resulted in the acceptable rate lower than $95 \%$ because nine participants reported the identification of different sets. Surveillance cultures for methicillin-resistant $S$. aureus and vancomycin-resistant enterococci were correctly determined by $89.6 \%$ and $69.0 \%$ of the respondents, respectively. Correct identification to species level of Candida albicans, Candida auris, Candida glabrata, and Candida parapsilosis were $86.1 \%, 1.6 \%, 48.1 \%$, and $83.8 \%$. Vancomycin disk diffusion test in $S$. aureus, missing oxacillin screen or penicillin susceptibility test in $S$. pneumoniae and lack of reliable methods of quinolone resistance detection in Salmonella species caused unacceptable results in antimicrobial susceptibility testing. Advanced bacteriology trials revealed low performance in species identification of mold. Mycobacterial culture, identification and susceptibility test performance was kept in excellence. The performance of identification of stool parasites was acceptable $>90 \%$ for detection of helminth eggs and amebic cysts but $28.6 \%$ false positive responses resulted from negative specimens. In conclusion, species-level identification of fungi of both candida species and mold were challenging to clinical microbiology laboratories. Vancomycin disk diffusion method for $S$. aureus and lack of proper penicillin susceptibility test for $S$. pneumoniae were still common cause of inaccurate results. Virtual microscopic survey has been successfully introduced in parasitology.

(J Lab Med Qual Assur 2015;37:153-178)

Key Words: Proficiency survey, Parasitology, Bacteriology, Clinical microbiology, Mycobacterial culture, Susceptibility testing 


\title{
Journal of LABORATORY MEDICINE and QUALITY ASSURANCE
}

\author{
Young Jin Ko et al • Annual EQA for Clinical Microbiology 2014
}

\section{서론}

대한임상검사정도관리협회 임상미생물학분과는 전체 분과 신빙도조사 참여기관들을 대상으로 그람염색, 항산균염색, 세 균 배양동정과 감수성 검사에 관한 신빙도조사 기본 모듈을 실 시하고, 자발적인 참여신청기관을 대상으로 항산균배양 및 동 정, 항결핵제 감수성 검사, 항결핵제 신속내성 검사, 까다로운 세균, 혐기성세균, 미호기성세균, 털곰팡이류 등을 포함하는 심화세균배양과 동정검사 등 네 가지 선택 모듈의 신빙도조사 를 제공하고 있다.

국제적으로 임상미생물학 검사실의 질 향상과 유지를 위 해 미국의 College of American Pathologist (CAP), 영국의 United Kingdom National External Quality Assessment Scheme, 세계보건기구(World Health Organization, WHO) 에서 다양한 수준의 신빙도조사를 실시하고 있다[1-3]. CAP 은 가장 광범위한 신빙도조사 프로그램을 제공하지만, 국내 검사실들이 참여하기에는 고비용이고, $\mathrm{WHO}$ 는 무료이지만, $\mathrm{WHO}$ 의 관심사인 결핵이나 항균제 내성균 검출에만 집중하 는 프로그램을 운영한다.

대한임상검사정도관리협회 임상미생물학분과는 국내 임상 미생물검사실의 수준이 발전하는 데 따라 모든 항목들에 대해 종합적인 신빙도조사 프로그램을 제공하는 것을 목표로 지난 10 년간 모듈을 확대해왔지만, 아직 미흡한 부분이 있다. 기생 충학을 위해 대변 기생충동정을 위한 선택모듈을 시범사업으 로 실시했고, 연구 모듈로 털곰팡이류 동정을 위한 조사 1회, 카바페넴 내성 장내세균 선별 및 확인검사 1 회 등 3 가지 새로 운 모듈을 시도하였고, 이를 바탕으로 이들 분야에 대해 신빙 도조사 사업을 지속적으로 실시하고자 한다. 하지만 임상미생 물학 분야에서 가장 새롭고 빠르게 발전하고 있는 바이러스 배 양, 항원, 항체검사와 감염분자진단 분야에 대한 신빙도조사가 실시된 적이 없어서 이를 위한 모듈 개발이 시급하다. 2014년 에도 항균제감수성 검사 부분은 최근의 중요한 판독기준과 특 이적인 검사법을[4-6] 반영할 수 있는 다양한 시도를 하였다.

임상미생물학분과는 2014년 전국적인 신빙도조사에서 각 모듈별 결과를 종합적으로 분석하고, 질 관리수준, 문제점 분 석, 향상방안 등을 제시하고자 하였다. 특히 Salmonella 종의 fluoroquinolone 내성 검출의 질 향상이 필요함을 제시하였다.

\section{재료 및 방법}

\section{1. 신빙도조사 방법}

2014 년 신빙도조사 사업은 $3,6,9$ 월에 걸쳐 3 회 검체를 발
송했으며, 그람염색, 항산균염색, 일반세균의 배양, 동정, 감수 성 검사는 다섯 검체씩 모든 참여기관에 배부하였다. 항산균염 색용 슬라이드는 대한결핵연구원에서 객담 검체에 항산균을 정량결과 기대치에 따라 배합한 후 멸균처리하여 유리슬라이 드에 도말을 하여 다섯 검체씩 배부하였다 그람염색, 일반세균 의 배양, 동정, 감수성 검사는 검체는 생균을 이용하여 Amies 운송배지(Copan Italia S.P.A., Brescia, Italy)에 담긴 면봉 검체를 다섯 개씩 만들었고, 임상 검체를 가상하여 가상환자의 임상적인 배경을 제시하였고, 다양한 검체와 임상상황을 조건 으로 임상적으로 의미 있는 수준의 배양과 동정을 하도록 요구 하였다. 각 생균 검체는 Amies 운송배지에서 생존능을 실온에 서 1 주일간 매일 계대배양하여 검증하였다. 항균제감수성 검 사 또한 균종과 검체에 따라 적절하게 선택하고, 판독하는지 검증하고자 하였다. 각 차수에 일반세균검사 분야는 기관별로 다섯 가지의 균주를 한 세트로 배부하였으며, 3 가지 세트를 준 비하여 한 세트가 참여기관 삼분의 일 정도씩 배부되도록 무작 위로 배정하였다. 특수세균, 항산균 배양과 동정, 항결핵제 감 수성 검사, 결핵 신속내성 검사 등 네 가지 모듈은 참여를 신청 한 기관에 배부하였다. 특수세균 분야는 까다로운 세균, 혐기 성 세균, 미호기성 세균, 털곰팡이류 진균 등 난이도가 높은 균 주를 각 차수별로 2 개씩 구성하여 참여를 신청한 기관에 배부 하였다. Amies 운송배지로 생존능을 만족할만큼 유지할 수 없 을 때는 냉동동결건조를 하여 배부하였다. 항산균 배양과 동 정, 항결핵제 감수성 검사, 결핵 신속내성 검사에 대한 검체는 각각 $5,5,2$ 개씩 대한결핵연구원에서 생균상태로 준비하였다. 모든 신청과 결과입력, 결과판정 등은 대한임상검사정도관리 협회 홈페이지에 구축된 임상미생물학분과 신빙도조사 프로 그램(http://keqas.org/)을 이용하였다.

\section{2. 관리물질}

그람염색, 세균배양 동정, 감수성 검사는 1차는 M1401-M1405, 2차 M1421-M1425, 3차 M1431-M1435 등 5개씩 검체를 준 비하였고, M1404, M1412, M1413, M1422, M1423 등은 각 2 종류의 검체를 준비하여 조합함으로써 $\mathrm{A}, \mathrm{B}, \mathrm{C}$ 3가지 세트를 구성하였다. 모든 시도에서 5 개의 일반배양 검체는 그람염색, 배양과 동정을 실시하고, 각 회차의 앞 번호 두 개의 검체에 대 해 항균제 감수성 검사를 같이 실시하도록 하였다. 모든 세균 과 진균은 서울아산병원 진단검사의학과에서 배양된 임상분 리주들이었다. 세균은 혈액한천배지 또는 쵸콜렛 한천배지에 키우고, 진균은 SDA (Sabouraud Dextrose Agar) 한천배지 에 키워서 얻은 집락을 배부하여 검사하도록 하였다. 모든 검 체는 운송을 위해 Amies 배지 또는 charcoal이 포함된 Amies 


\title{
Journal of LABORATORY MEDICINE and QUALITY ASSURANCE
}

\author{
Young Jin Ko et al • Annual EQA for Clinical Microbiology 2014
}

배지에 담긴 면봉(Copan Italia)에 도말 검체상태로 운송하였 다. 특수세균 분야는 1차 S1401, S1402, 2차 S1403, S1404, 3 차 S1405, S1406 등 차수별로 2개씩 구성하였다. 감염성 검체 의 안전한 운송과 생존능 보존을 위해 모든 검체는 녹십자임상 검사센터와 서울임상검사센터의 임상 검체 배송시스템을 통 해 전국 참여기관에 다음날까지 배송하도록 하였다.

항산균도말은 1차 M1406-M1410, 2차 M1416-M1420, 3차 M1426-M1430 등 5개씩 도말 검체를 배부하였고, 항산균 배 양과 동정 검체는 1, 2차에 T1401-T1405, T1411-T1415 각 5 개씩 생균을 배합한 객담 검체를 배부하였고, 항결핵제 감수성 검사용으로 1, 2차에 T1406-T1410, T1416-T1420, 각 5개씩 Ogawa 배지에 자란 집락을 배부하였고, 결핵 신속내성 검사 용으로 1차에 R1401, R1402, 2차에 R1403, R1404 각 2개씩 생균을 배합한 객담 검체를 배부하였다.

기생충학은 대변 기생충 검사 도말 슬라이드 5 개를 400 배 배율까지 스캔하여 P1401-P1405까지 가상현미경프로그램에 등록하였다. 각 참여기관은 이 프로그램을 결과입력 사이트를 통해 접속할 수 있도록 하였다. 연구용 모듈로서 1차에 가톨릭 대학교 의과대학 이승옥교수가 털곰팡이류 배양 및 동정을 위 한 진균 검체 5 개, 3 차에 한림대학교 의과대학 송원근교수가 카바페넴 내성 장내세균에서 modified Hodge test (MHT)와 carbapenemase inhibition test 검사 수행능 평가를 위해 3개 검체를 Amies 운송배지에 면봉도말상태로 제작하여 배부하였다.

\section{3. 결과 판정 및 해석}

그람염색과 항산균염색은 검체당 2점씩 총 10점을 배점하 여 평가하였다. 항산균염색은 음성은 음성만을 정답 처리한 반 면, 양성은 정량값을 3 단계씩 묶었을 때 $90 \%$ 이상의 검사실 이 포함되는 3 단계를 모두 정답으로 처리하였다. 검체를 배부 할 때 검체종류, 검사항목, 결과 판정기준을 제시하였다. 균종 동정은 종수준까지 맞는 경우를 ‘우수(good)'로, 임상적으로 속수준의 동정이 의미가 있다면 속수준까지 맞는 경우를 '적 절(acceptable)'하다고 판정하였다. 이 기준에 맞지 않은 답 을 하거나 답하지 않은 경우 ‘부적절(not acceptable)'로 판정 하였다. 항균제감수성 검사는 균종별로 2014년 Clinical and Laboratory Standards Institute (CLSI) M100-S24의 기준 [5]에 따라 판정했으며, 가상 검체의 종류에 따라 기준을 달 리 적용하여 해석하였다. 감수성 검사방법을 잘못 적용하였거 나 감수성 검사결과 판독이 틀린 경우와 필수적인 항균제에 대 해 검사하지 않았거나 보고하지 않도록 권하는 항균제를 결과 에 포함시킨 경우 각 0.5 점씩 감점하였다. 15 기관 이상에서 감 수성 검사를 보고한 항균제에 대해서만 평가를 하였고, 전체
기관의 결과 값의 일치도가 $85 \%$ 에 미달이면 판정을 보류하였 지만, 참고방법으로 확인검사를 통해 정답을 판단할 수 있으 면 평가하였다. 균배양검사를 하지 않거나 배양에 실패한 경 우는 감수성 검사 배정점수를 총점에서 제외하였다. 동정검 사는 각 8점, 항균제감수성 검사는 두 검체에 대해서 각 20점 을 기준으로 하였다. 항산균 배양과 동정, 항결핵제 감수성 검 사, 결핵 신속내성 검사는 각각 100 점씩 배점하여 평가하였 다. Acid fast bacilli (AFB) 염색까지만 하고 동정을 하지 않 는 기관은 $\mathrm{AFB}$ 검출 여부로 평가를 했으며, 동정을 하는 기관 들에 대해서는 결핵과 비결핵항산균으로 동정하는 수준까지 를 acceptable로 해서 결핵을 비결핵으로 동정하거나 비결핵 을 결핵으로 동정하면 not acceptable로 평가했다. 종수준 동 정이 맞으면 good으로 평가했다. 특수세균, 기생충학 모듈, 연 구용모듈은 기관별 평가없이 해석적 보고만 하였다.

\section{결과}

2014년 임상미생물학분과 참여기관은 340기관이었고, 이 중 1차에서 330기관(97.0\%), 2차에서 331기관(97.4\%), 3차 에서 331기관(97.4\%)이 회신하였다. 3차례의 조사 중 M1425 Haemophilus parainfluenzae의 균배양에 실패한 기관이 과 반수여서 이 세균의 생존능도 잘 보존되지 못했던 것으로 판단 하고 평가에서 제외하였다. 다른 일반세균 검체는 균배양 실패 가 매우 드물었고, S1405 Corynebacterium jeikeium, S1406 Clostridium tertium 각 1기관씩만 배양실패를 답해서 전반적 으로 다른 조사물질은 생존능이 잘 유지되었던 것으로 추정하 였다. 항산균배양 및 동정은 1,2 차 86 기관이 신청하였고, 항 결핵제감수성 검사 6,7 기관, 결핵균 신속내성 검사는 23,24 기관이 참여하였다. 액체배지 배양기관은 응답한 79 기관 중 60 곳이고 고체배지를 병용하는 기관이 51 곳이었다. 특수세균 은 1차 91, 2차 86, 3차 85기관이 신청하였다. 기생충 검사는 118 기관이 신청하였다. 카바페네메제생산 장내세균 검출에 102 기관이 신청했으나 실제로 입력한 기관은 72 기관이었다.

\section{1. 그람염색과 항산균 염색}

$1,2,3$ 차 모두에서 그람염색은 $90 \%$ 이상, 항산균염색은 $95 \%$ 이상의 기관들이 정답을 보고하였다(Fig. 1). 3차 신빙도 조사에서 M1425 H. parainfluenzae가 평가에서 제외되어 그 람염색 배점이 총 8점이 되었다. 그람염색은 사무적인 입력오 류가 항상 비슷한 비율로 반복되어 차수와 상관없이 비슷한 점 수분포를 보였다. 


\section{Journal of LABORATORY MEDICINE and QUALITY ASSURANCE}

\section{Young Jin Ko et al • Annual EQA for Clinical Microbiology 2014}

A

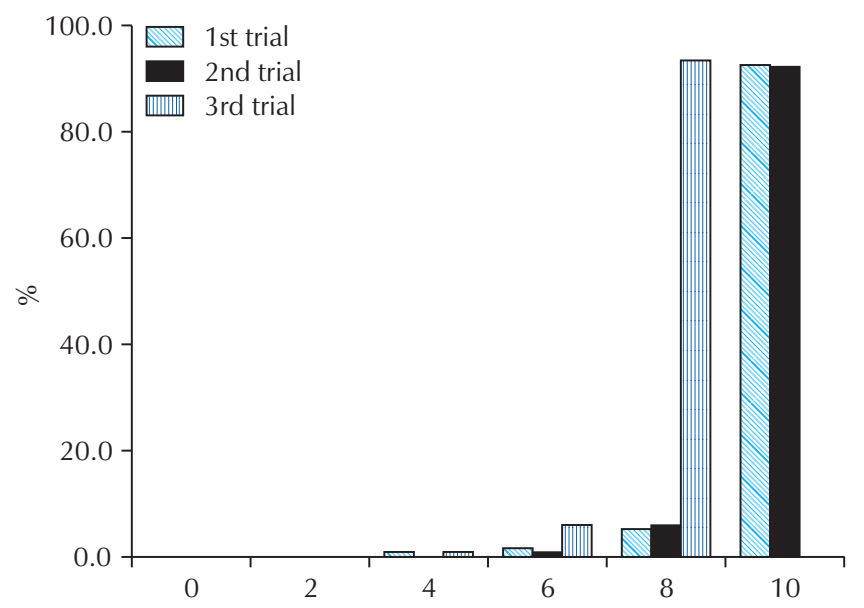

B

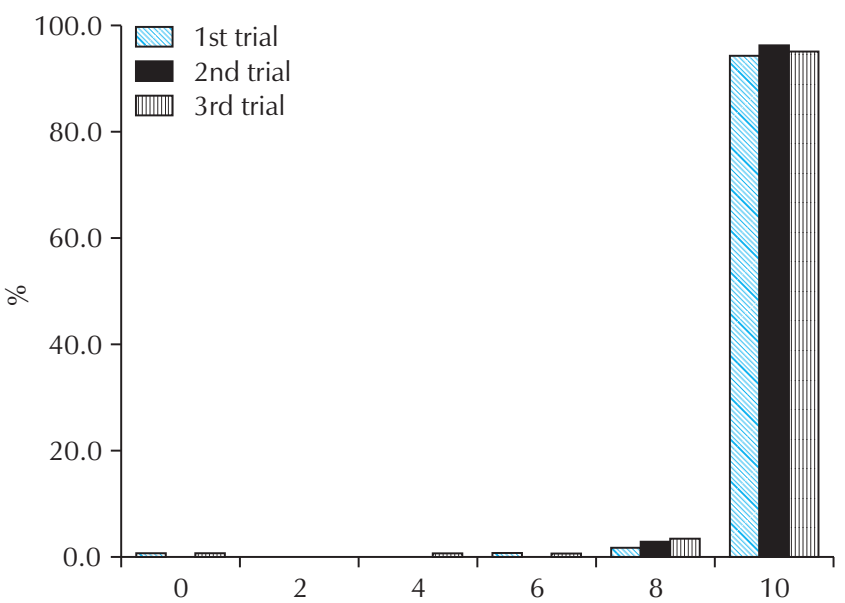

Fig. 1. Distribution of score accomplished by participating laboratories for the first, second and third trials of (A) Gram stain and (B) AFB stain.

\section{2. 세균 동정검사}

1차는 Burkholderia cepacia, Klebsiella pneumoniae, Streptococcus pyogenes, Candida albicans 균종 동정결과 의 acceptable\% (good\%)는 97.3 (95.0), 100 (100.0), 97.7 (97.7), 99.2 (89.6)으로 모든 균종의 동정 정확도가 $90.0 \%$ 이상으로 높았다. 2차는 M1411 Pseudomonas aeruginosa, M1412 Streptococcus pneumoniae, Streptococcus agalactiae, M1415 Plesiomonas shigelloides 종수준 동정률은 99\%, $96.9 \%, 98.4 \%, 91.5 \%$ 로 비교적 높았다. M1413 B, C set는 vancomycin-resistant enterococci (VRE) isolated로 보고한 기관이 $60 \%$ 에 불과하고 VRE not isolated가 $37 \%$ 였던 것은 대변 상재균으로 혼합시킨 반코마이신 감수성 Enterococcus faecalis를 분리동정해서 보고한 것으로 $\mathrm{VRE}$ 감시배양의 높은 오답률을 초래하였다. M1414 Candida auris는 종수 준 동정까지 정확한 기관은 4 기관에 불과하였다. 3 차에서 Salmonella 종은 serogroup까지 맞는 것을 good으로 평가하 였고, Salmonella 속 중 serovar Typhi, Paratyphi로 동정하 거나 다른 serogroup으로 동정하면 not acceptable로 평가하 였다. M1422의 Salmonella를 포함한 검체가 혈액임에도 불 구하고, 검체 준비과정에서 대변 검체에 준해서 장관의 정상상 재균인 Escherichia coli를 섞는 오류가 발생해서 검체우송 후 이 균을 제외하도록 공지하였고, 한 기관만 E. coli를 동정보고 하였다. M1421 Staphylococcus aureus, M1422 Salmonella group C, Salmonella group D, M1423 Candida glabrata, Candida parapsilosis, M1424 Enterococcus faecium의 동정 정확도는 acceptable\% (good\%)가 99.6\% (99.6\%), 94.4\% (80.7\%), 89.1\% (75.0\%)이었다, M1422 검체에 대해 다른
세트의 serogroup을 보고한 기관이 총 9곳이 있었고, M1423 검체의 $\mathrm{A}$ 세트 검체를 받았는데 C. parapsilosis로 보고한 곳이 4곳, $\mathrm{B}, \mathrm{C}$ 세트의 검체를 받았는데 C. glabrata로 보고한 기관 이 1 곳으로 여전히 다른 기관과 검사결과를 공유하는 곳이 있 다고 추정되었다(Table 1).

\section{3. 항균제감수성 검사}

M1401 B. cepacia의 ceftazidime에 대한 디스크확산법 감 수성 검사 억제대가 $25 \mathrm{~mm}$ 로 확실한 감수성인데도 minimal inhibitory concentration (MIC)법으로 검사한 기관에서 I 또는 $\mathrm{R}$ 로 보고한 기관 16 곳 $(7.7 \%)$ 은 모두 MicroScan (Siemens, Sacramento, CA, USA)을 사용하였고, MicroScan NC44 패 널에 반복적으로 검사하면 MIC가 $8 \mu \mathrm{g} / \mathrm{mL}$ (S)와 $16 \mu \mathrm{g} / \mathrm{mL}$ (I)가 교대로 나와 2 배 희석배수 안에서 결과가 바뀌는 내성 쪽으로 편향된 오류가 발생하였다(Table 2).

M1402 DHA-1 plasmid-mediated AmpC $\beta$-lactamase 에 의해 광범위 세팔로스포린에 내성인 K. pneumoniae 에 대해 Vitek2를 사용하는 기관에서 extended-spectrum $\beta$-lactamase (ESBL) 양성으로 판독하여 검사기관의 $30 \%$ 가 위양성으로 보고하였다. Amikacin, gentamicin의 일치율이 매우 낮았는데 디스크확산법으로 감수성기관은 $76 \%, 72 \%$ 에 서 내성으로 보고하였는데, MIC법에서는 Vitek2 (bioMerieux $\mathrm{SA}$, Marcy l'Etoile, France) 사용 기관에서 다수가 감수성 으로 보고하였다(Table 3). 디스크확산법에서 이중 억제대 (double zone) 현상으로 안쪽 직경이 amikacin, gentamicin, tobramycin, arbekacin 모두 $6 \mathrm{~mm}$ 로 확실한 내성이었으며, arbekacin까지 내성을 초래하는 $16 \mathrm{rRNA}$ methylase에 의한 
Young Jin Ko et al • Annual EQA for Clinical Microbiology 2014

Table 1. Performance of species identification in general bacteriology

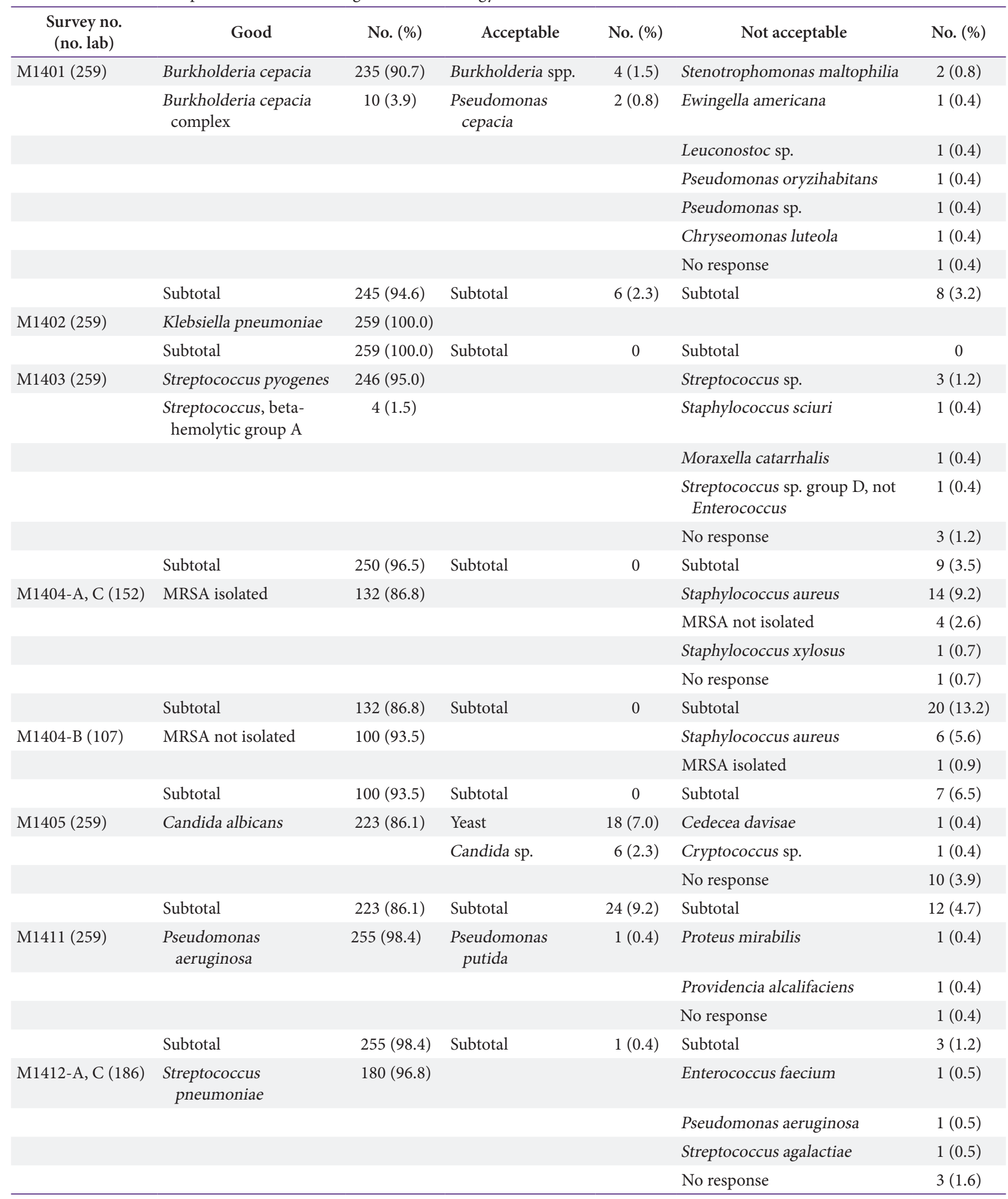


Journal of LABORATORY MEDICINE and QUALITY ASSURANCE

Young Jin Ko et al • Annual EQA for Clinical Microbiology 2014

Table 1. Continued

\begin{tabular}{|c|c|c|c|c|c|c|}
\hline $\begin{array}{l}\text { Survey no. } \\
\text { (no. lab) }\end{array}$ & Good & No. (\%) & Acceptable & No. $(\%)$ & Not acceptable & No. $(\%)$ \\
\hline & Subtotal & $180(96.8)$ & Subtotal & 0 & Subtotal & $6(3.2)$ \\
\hline \multirow[t]{5}{*}{ M1412-B (73) } & $\begin{array}{l}\text { Streptococcus } \\
\text { agalactiae }\end{array}$ & $65(89.0)$ & Streptococcus species & $2(2.7)$ & Streptococcus pneumoniae & $2(2.7)$ \\
\hline & & & & & Streptococcus pyogenes & $1(1.4)$ \\
\hline & & & & & Leuconostoc species & $1(1.4)$ \\
\hline & & & & & No response & $2(2.7)$ \\
\hline & Subtotal & $65(89.0)$ & Subtotal & $2(2.7)$ & Subtotal & $6(8.3)$ \\
\hline \multirow[t]{4}{*}{ M1413-A (87) } & VRE not isolated & $76(87.4)$ & & & VRE isolated & $7(8.0)$ \\
\hline & & & & & Enterococcus faecium & $3(3.4)$ \\
\hline & & & & & No response & $1(1.1)$ \\
\hline & Subtotal & $76(87.4)$ & Subtotal & 0 & Subtotal & $11(12.6)$ \\
\hline \multirow[t]{6}{*}{ M1413-B, C (172) } & VRE isolated & $102(59.3)$ & & & VRE not isolated & $63(36.6)$ \\
\hline & & & & & Enterococcus faecium & $4(2.3)$ \\
\hline & & & & & Klebsiella oxytoca & $1(0.6)$ \\
\hline & & & & & Staphylococcus, coagulase-neg & $1(0.6)$ \\
\hline & & & & & No response & $1(0.6)$ \\
\hline & Subtotal & $102(59.3)$ & Subtotal & 0 & Subtotal & $69(40.7)$ \\
\hline \multirow[t]{6}{*}{ M1414 (256) } & Candida auris & $4(1.6)$ & Candida haemulonii & $171(66.8)$ & Rhodotorula mucilaginosa (rubra) & $2(0.8)$ \\
\hline & & & Candida species & $21(8.2)$ & Rhodotorula glutinis & $8(3.1)$ \\
\hline & & & $\begin{array}{r}\text { Candida not } \\
\text { C. albicans }\end{array}$ & $9(3.5)$ & No response & $5(2.0)$ \\
\hline & & & Candida lusitaniae & $2(0.8)$ & & \\
\hline & & & Yeast & $34(13.3)$ & & \\
\hline & Subtotal & $4(1.6)$ & Subtotal & $237(92.5)$ & Subtotal & $15(5.9)$ \\
\hline \multirow[t]{10}{*}{ M1415 (259) } & $\begin{array}{l}\text { Plesiomonas } \\
\text { shigelloides }\end{array}$ & $249(96.1)$ & & & Aerococcus viridans & $1(0.4)$ \\
\hline & & & & & Aeromonas hydrophila & $1(0.4)$ \\
\hline & & & & & Enterobacter sakazakii & $1(0.4)$ \\
\hline & & & & & Escherichia coli & $1(0.4)$ \\
\hline & & & & & Providencia stuartii & $1(0.4)$ \\
\hline & & & & & Staphylococcus sp. not S. aureus & $1(0.4)$ \\
\hline & & & & & Vibrio cholerae & $1(0.4)$ \\
\hline & & & & & Vibrio vulnificus & $1(0.4)$ \\
\hline & & & & & No response & $2(0.8)$ \\
\hline & Subtotal & $249(96.1)$ & Subtotal & 0 & Subtotal & $10(4.9)$ \\
\hline \multirow[t]{2}{*}{ M1421 (262) } & $\begin{array}{l}\text { Staphylococcus } \\
\text { aureus }\end{array}$ & $243(92.7)$ & MRSA isolated & $18(6.9)$ & Staphylococcus xylosus & $1(0.4)$ \\
\hline & Subtotal & $243(92.7)$ & Subtotal & $18(6.9)$ & Subtotal & $1(0.4)$ \\
\hline \multirow[t]{2}{*}{ M1422-A, B (197) } & Salmonella spp. C & $157(79.7)$ & Salmonella spp. & $27(13.7)$ & Salmonella spp. D, not S. Typhi & $3(1.5)$ \\
\hline & $\begin{array}{l}\text { Salmonella spp. } \\
\text { C1 }\end{array}$ & $2(1.0)$ & $\begin{array}{l}\text { Salmonella spp. not } \\
\text { S. Typhi }\end{array}$ & $2(1.0)$ & Salmonella Paratyphi A & $2(1.0)$ \\
\hline
\end{tabular}

(Continued to the next page) 
Journal of LABORATORY MEDICINE and QUALITY ASSURANCE

Young Jin Ko et al • Annual EQA for Clinical Microbiology 2014

Table 1. Continued

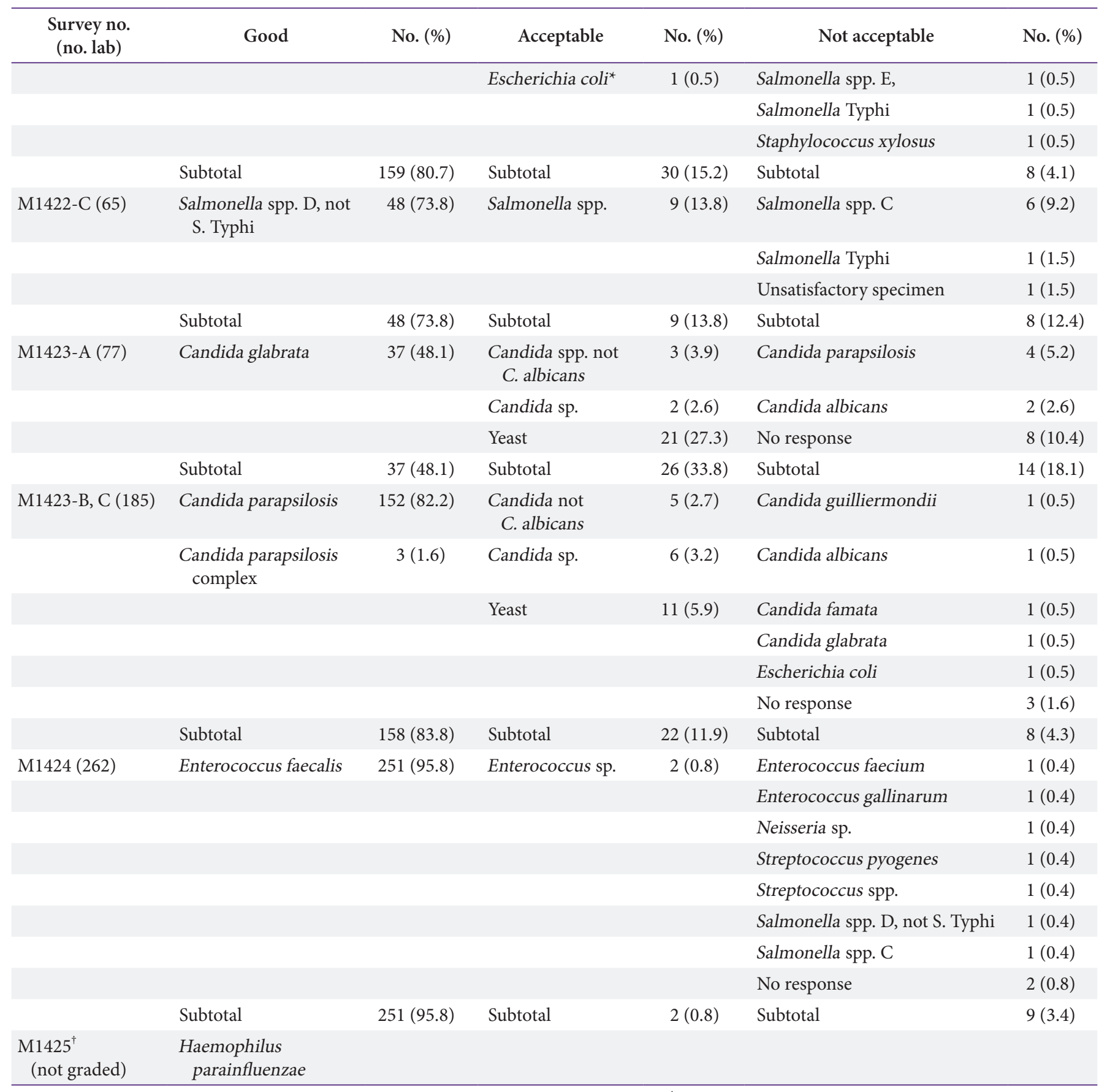

${ }^{\star}$ Escherichia coli was contained in the survey materials for purpose of contamination; ${ }^{\dagger}$ Not graded due to poor viability of survey material.

내성기전을 가지고 있을 것으로 추정되었다.

M1411 P. aeruginosa는 imipenem, meropenem Etest $\mathrm{MIC}$ 가 각각 $12,4 \mu \mathrm{g} / \mathrm{mL}$ 로 2012 년 이후의 CLSI breakpoint 를 적용하면 $\mathrm{R}$ 과 $\mathrm{S}$ 에 해당한다. 디스크억제대 직경도 15,16 $\mathrm{mm}$ 로 $\mathrm{MIC}$ 에 일치하였다. Imipenem MIC 검사기관 199 개
중 188 개 기관이 내성, 11 개 기관이 I로 보고하여 내성이 확실 했던 데 비해 meropenem MIC 결과를 보고한 148 개 기관 중 $\mathrm{S}, \mathrm{I}, \mathrm{R}$ 분포가 $52,71,25$ 기관씩으로 일치도가 낮아서 평가에 서 제외하였다(Table 4). MicroScan 장비를 사용했다고 답 한 31 기관 중 17 기관, Vitek 장비를 사용했다고 답한 105 기관 


\section{Journal of LABORATORY MEDICINE and QUALITY ASSURANCE}

Young Jin Ko et al • Annual EQA for Clinical Microbiology 2014

Table 2. Performance of antimicrobial susceptibility test of M1401 Burkholderia cepacia

\begin{tabular}{|c|c|c|c|c|c|c|c|c|c|c|c|c|}
\hline \multirow{2}{*}{ Antimicrobials } & \multicolumn{6}{|c|}{ Disk diffusion method } & \multicolumn{6}{|c|}{ Commercial broth dilution method } \\
\hline & No. lab & $\mathrm{S}$ & I & $\mathrm{R}$ & Criteria & $\%$ & No. lab & $S$ & I & $\mathrm{R}$ & Criteria & $\%$ \\
\hline Amikacin & 16 & 2 & 1 & 13 & IA & & 9 & & & 9 & IA & \\
\hline Amoxicillin/Cla & 2 & & & 2 & IA & & 3 & & & 3 & IA & \\
\hline Ampicillin & 6 & & & 6 & IA & & 4 & & & 4 & IA & \\
\hline Ampicillin/Sul & 3 & & & 3 & IA & & 4 & & & 4 & IA & \\
\hline Aztreonam & 10 & 2 & 7 & 1 & IA & & 7 & 1 & 4 & 2 & IA & \\
\hline Cefazolin & 2 & & & 2 & IA & & 3 & & & 3 & IA & \\
\hline Cefepime & 3 & 2 & 1 & & IA & & 12 & 11 & & 1 & IA & \\
\hline Cefoperazone & 1 & & & 1 & IA & & & & & & IA & \\
\hline Cefoperazone/Sul & 1 & & 1 & & IA & & & & & & IA & \\
\hline Cefotaxime & 8 & 4 & 4 & & IA & & 10 & 8 & & 2 & IA & \\
\hline Cefotetan & 1 & & 1 & & IA & & & & & & IA & \\
\hline Cefoxitin & & & & & IA & & 2 & & & 2 & IA & \\
\hline Ceftazidime & 35 & 34 & & 1 & S & 97.1 & 208 & 192 & 7 & 9 & $\mathrm{~S}$ & 92.3 \\
\hline Ceftriaxone & 10 & 6 & 4 & & IA & & 1 & & & 1 & IA & \\
\hline Cefuroxime axetil & 1 & & 1 & & IA & & & & & & IA & \\
\hline Cefuroxime Sod & 1 & & & 1 & IA & & & & & & IA & \\
\hline Cephalothin & 1 & & & 1 & IA & & & & & & IA & \\
\hline Chloramphenicol & 1 & 1 & & & MIC & & 7 & 7 & & & $S$ & 100.0 \\
\hline Ciprofloxacin & 17 & 17 & & & IA & & 15 & 2 & & 13 & IA & \\
\hline Colistin & 1 & & & 1 & IA & & 1 & & & 1 & IA & \\
\hline Doxycycline & 1 & 1 & & & IA & & & & & & IA & \\
\hline Gentamicin & 13 & 1 & & 12 & IA & & 10 & & & 10 & IA & \\
\hline Imipenem & 14 & 13 & & 1 & IA & & 11 & & 3 & 8 & IA & \\
\hline Levofloxacin & 7 & 7 & & & MIC & & 74 & 72 & 2 & & $S$ & 97.3 \\
\hline Meropenem & 17 & 16 & 1 & & S & 94.1 & 205 & 205 & & & S & 100.0 \\
\hline Minocycline & 9 & 9 & & & S & 100.0 & 140 & 138 & 1 & 1 & S & 98.6 \\
\hline Netilmicin & 6 & & 1 & 5 & IA & & & & & & IA & \\
\hline Piperacillin & 10 & 9 & & 1 & IA & & 11 & 10 & 1 & & IA & \\
\hline Piperacillin/Taz & 3 & 3 & & & IA & & 12 & & & 12 & IA & \\
\hline Rifampin & 1 & & & 1 & IA & & & & & & IA & \\
\hline Ticarcillin & 1 & & & 1 & IA & & & & & & IA & \\
\hline Ticarcillin/Cla & 2 & & & 2 & MIC & & 150 & & & 150 & $\mathrm{R}$ & 100.0 \\
\hline Tigecycline & & & & & IA & & 10 & 10 & & & IA & \\
\hline Tobramycin & 8 & & & 8 & IA & & & & & & IA & \\
\hline TMP-SMX & 28 & 28 & & & S & 100.0 & 205 & 204 & & 1 & $S$ & 99.5 \\
\hline ESBL & & & & & & & 1 & & & Pos & IA & \\
\hline
\end{tabular}

Abbreviations: S, susceptible; I, intermediate; R, resistance; Amoxicillin/Cla, Amoxicillin/clavulanic acid; Ampicillin/Sul, Ampicillin/ sulbactam; Piperacillin/Taz, Piperacillin/tazobactam; Ticarcillin/Cla, Ticarcillin/clavulanic acid; TMP-SMX, trimethoprim-sulfamethoxazole; ESBL, extended-spectrum $\beta$-lactamase. 
Journal of LABORATORY MEDICINE and QUALITY ASSURANCE

Young Jin Ko et al • Annual EQA for Clinical Microbiology 2014

Table 3. Performance of antimicrobial susceptibility test of M1402 Klebsiella pneumoniae

\begin{tabular}{|c|c|c|c|c|c|c|c|c|c|c|c|c|}
\hline \multirow{2}{*}{ Antimicrobials } & \multicolumn{6}{|c|}{ Disk diffusion method } & \multicolumn{6}{|c|}{ Commercial broth dilution method } \\
\hline & No. lab & $S$ & $\mathrm{I}$ & $\mathrm{R}$ & Criteria & $\%$ & No. lab & $\mathrm{S}$ & $\mathrm{I}$ & $\mathrm{R}$ & Criteria & $\%$ \\
\hline Amikacin & 17 & 16 & & 1 & $\mathrm{~S}$ & 94.1 & 57 & 57 & & & $\mathrm{~S}$ & 100.0 \\
\hline Amoxicillin/Cla & 9 & 9 & & & S & 100.0 & 35 & 35 & & & S & 100.0 \\
\hline Ampicillin & 16 & 1 & & 15 & $\mathrm{R}$ & 93.8 & 61 & & 3 & 58 & $\mathrm{R}$ & 95.1 \\
\hline Ampicillin/Sul & 4 & 3 & & 1 & $\mathrm{~S}$ & 75.0 & 9 & 9 & & & S & 100.0 \\
\hline Aztreonam & 5 & 5 & & & S & 100.0 & 8 & 8 & & & S & 100.0 \\
\hline Cefamandole & 1 & 1 & & & & & & & & & & \\
\hline Cefazolin & 7 & 6 & 1 & & S & 85.7 & 51 & 49 & 1 & 1 & $\mathrm{~S}$ & 96.1 \\
\hline Cefepime & 4 & 4 & & & $\mathrm{~S}$ & 100.0 & 51 & 51 & & & S & 100.0 \\
\hline Cefmetazole & 1 & 1 & & & & & & & & & & \\
\hline Cefoperazone & 1 & 1 & & & & & & & & & & \\
\hline Cefotaxime & 12 & 12 & & & S & 100.0 & 53 & 53 & & & S & 100.0 \\
\hline Cefotetan & 2 & 2 & & & & & 2 & 2 & & & $\mathrm{~S}$ & 100.0 \\
\hline Cefoxitin & 1 & 1 & & & S & 100.0 & 37 & 37 & & & S & 100.0 \\
\hline Ceftazidime & 10 & 10 & & & S & 100.0 & 9 & 9 & & & S & 100.0 \\
\hline Ceftriaxone & 9 & 9 & & & & & & & & & & \\
\hline Cefuroxime axetil & 1 & 1 & & & & & & & & & & \\
\hline Cefuroxime sod & 2 & 2 & & & & & & & & & & \\
\hline Cephalothin & 5 & 5 & & & Urine & Only & & & & & & \\
\hline Chloramphenicol & 3 & 3 & & & & & & & & & & \\
\hline Ciprofloxacin & 19 & 19 & & & $\mathrm{~S}$ & 100.0 & 43 & 43 & & & S & 100.0 \\
\hline Ertapenem & & & & & & & 22 & 22 & & & S & 100.0 \\
\hline Gentamicin & 18 & 18 & & & S & 100.0 & 67 & 67 & & & S & 100.0 \\
\hline Imipenem & 14 & 14 & & & S & 100.0 & 50 & 50 & & & S & 100.0 \\
\hline Kanamycin & 1 & 1 & & & & & & & & & & \\
\hline Levofloxacin & 2 & 2 & & & S & & 7 & 7 & & & $\mathrm{~S}$ & 100.0 \\
\hline Meropenem & 6 & 6 & & & $\mathrm{~S}$ & 100.0 & 7 & 7 & & & S & 100.0 \\
\hline Netilmicin & 3 & 3 & & & & & & & & & & \\
\hline Piperacillin & 6 & 6 & & & S & 100.0 & 8 & 7 & 1 & & $\mathrm{~S}$ & 87.5 \\
\hline Piperacillin/Taz & 2 & 2 & & & $\mathrm{~S}$ & 100.0 & 28 & 28 & & & $\mathrm{~S}$ & 100.0 \\
\hline Rifampin & 1 & & & 1 & IA & & & & & & & \\
\hline Tetracycline & 3 & 3 & & & $\mathrm{R}$ & & & & & & & \\
\hline Ticarcillin & 1 & & & 1 & $\mathrm{R}$ & 100.0 & & & & & & \\
\hline Ticarcillin/Clav & 1 & 1 & & & & & 1 & 1 & & & & \\
\hline Tigecycline & & & & & & & 1 & 1 & & & IA & \\
\hline Tobramycin & 5 & 4 & & 1 & $\mathrm{~S}$ & 80.0 & 8 & 8 & & & S & 100.0 \\
\hline TMP-SMX & 13 & 13 & & & $S$ & 100.0 & 46 & 46 & & & $\mathrm{~S}$ & 100.0 \\
\hline ESBL & & & & & & & 34 & $\mathrm{Neg}$ & & & Neg & 100.0 \\
\hline
\end{tabular}

Abbreviations: S, susceptible; I, intermediate; R, resistance; Amoxicillin/Cla, Amoxicillin/clavulanic acid; Ampicillin/Sul, Ampicillin/ sulbactam; Piperacillin/Taz, Piperacillin/tazobactam; Ticarcillin/Cla, Ticarcillin/clavulanic acid; TMP-SMX, trimethoprim-sulfamethoxazole; ESBL, extended-spectrum $\beta$-lactamase. 


\section{Journal of LABORATORY MEDICINE and QUALITY ASSURANCE}

Young Jin Ko et al • Annual EQA for Clinical Microbiology 2014

Table 4. Performance of antimicrobial susceptibility test of M1411 Pseudomonas aeruginosa

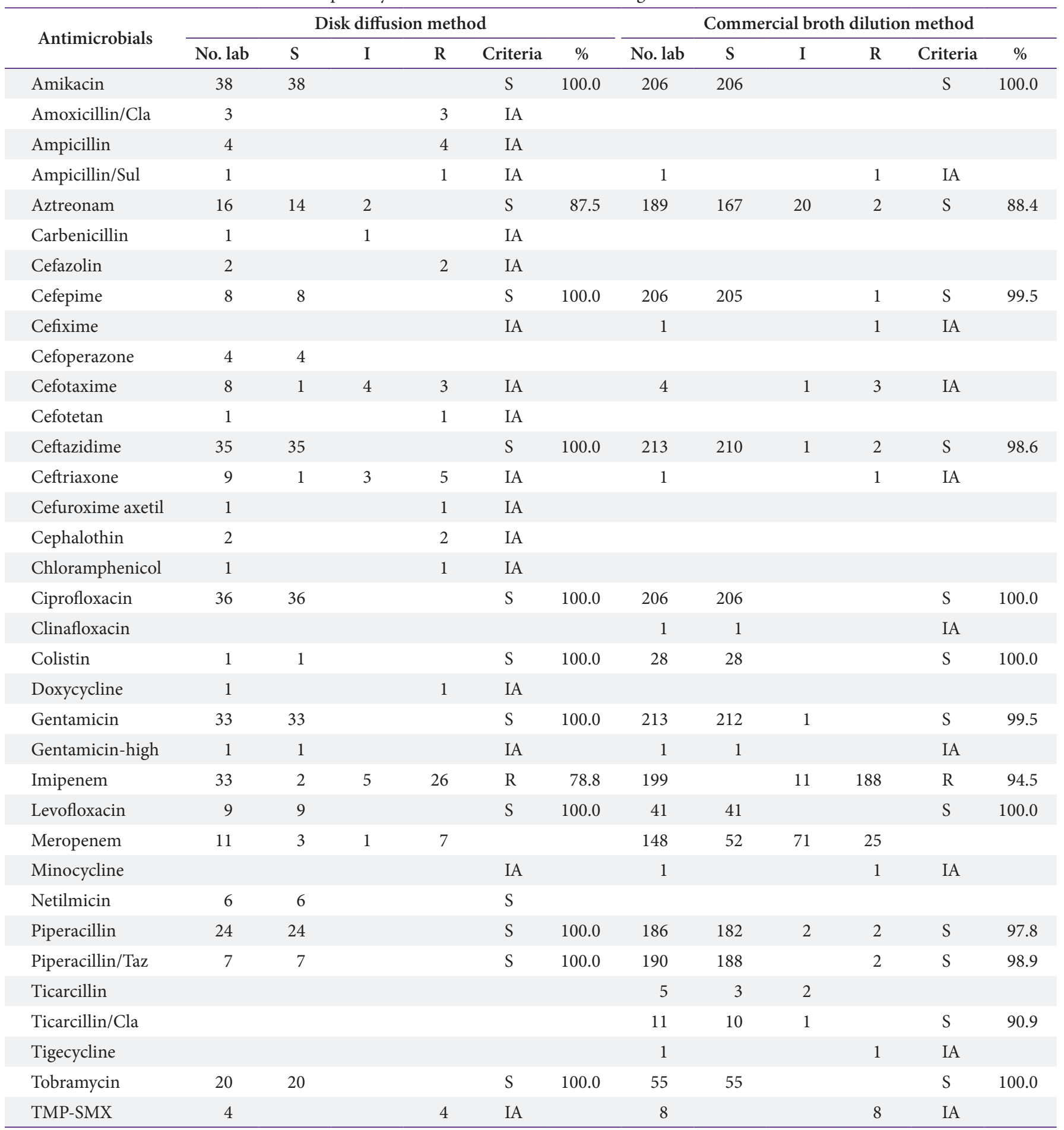

Abbreviations: S, susceptible; I, intermediate; R, resistance; Amoxicillin/Cla, Amoxicillin/clavulanic acid; Ampicillin/Sul, Ampicillin/ sulbactam; Piperacillin/Taz, Piperacillin/tazobactam; Ticarcillin/Cla, Ticarcillin/clavulanic acid; TMP-SMX, trimethoprim-sulfamethoxazole; ESBL, extended-spectrum $\beta$-lactamase. 


\section{Journal of LABORATORY MEDICINE and QUALITY ASSURANCE}

\section{Young Jin Ko et al • Annual EQA for Clinical Microbiology 2014}

Table 5. Performance of antimicrobial susceptibility test of M1412-A, C Streptococcus pneumoniae

\begin{tabular}{|c|c|c|c|c|c|c|c|c|c|c|c|c|}
\hline \multirow{2}{*}{ Antimicrobials } & \multicolumn{6}{|c|}{ Disk diffusion method } & \multicolumn{6}{|c|}{ Commercial broth dilution method } \\
\hline & No. lab & $S$ & I & $\mathrm{R}$ & Criteria & $\%$ & No. lab & $S$ & $\mathrm{I}$ & $\mathrm{R}$ & Criteria & $\%$ \\
\hline Amoxicillin/Cla & 1 & 1 & & & MIC & & 4 & 4 & & & & \\
\hline Ampicillin & & & & & & & 2 & 2 & & & & \\
\hline Azithromycin & & & & & & & 1 & 1 & & & & \\
\hline Cefepime & 2 & 2 & & & MIC & & 26 & 26 & & & $S$ & 100.0 \\
\hline Cefotaxime & 3 & 2 & & 1 & MIC & & 146 & 146 & & & S & 100.0 \\
\hline Cefoxitin & 1 & & & 1 & IA & & & & & & & \\
\hline Ceftriaxone & 3 & 3 & & & MIC & & 123 & 123 & & & S & 100.0 \\
\hline Cefuroxime & 1 & 1 & & & MIC & & & & & & & \\
\hline Chloramphenicol & 7 & 7 & & & $\mathrm{~S}$ & 100.0 & 7 & 7 & & & $S$ & 100.0 \\
\hline Ciprofloxacin & 1 & & & 1 & IA & & & & & & & \\
\hline Clindamycin & 19 & 3 & & 16 & $\mathrm{R}$ & 84.2 & 142 & 22 & & 120 & $\mathrm{R}$ & 84.5 \\
\hline Daptomycin & & & & & & & 1 & 1 & & & & \\
\hline Erythromycin & 24 & & & 24 & $\mathrm{R}$ & 100.0 & 149 & 6 & 1 & 142 & $\mathrm{R}$ & 95.3 \\
\hline Gentamicin & 1 & & & 1 & IA & & & & & & & \\
\hline Imipenem & 3 & 2 & & 1 & & & & & & & & \\
\hline Levofloxacin & 6 & 6 & & & $\mathrm{~S}$ & 100.0 & 147 & 147 & & & $S$ & 100.0 \\
\hline Linezolid & 3 & 3 & & & S & 100.0 & 94 & 94 & & & $S$ & 100.0 \\
\hline Meropenem & & & & & & & 26 & 26 & & & $S$ & 100.0 \\
\hline Moxifloxacin & & & & & & & 2 & 2 & & & & \\
\hline Ofloxacin & 4 & 4 & & & & & & & & & & \\
\hline Oxacillin (screen) & 10 & 8 & & 2 & $S$ & 80.0 & & & & & & \\
\hline Penicillin G & 10 & 10 & & & S & 100.0 & 153 & 152 & 1 & & S & 99.3 \\
\hline Rifampin & & & & & & & 1 & 1 & & & & \\
\hline Teicoplanin & 3 & 2 & & 1 & & & & & & & & \\
\hline Tetracycline & 10 & & & 10 & $\mathrm{R}$ & 100.0 & 142 & 4 & 2 & 136 & $\mathrm{R}$ & 95.8 \\
\hline TMP-SMX & 16 & 3 & 3 & 12 & & & 149 & 44 & 70 & 35 & & \\
\hline Vancomycin & 25 & 25 & & & S & 100.0 & 152 & 152 & & & $S$ & 100.0 \\
\hline
\end{tabular}

Abbreviations: S, susceptible; I, intermediate; R, resistance; Amoxicillin/Cla, Amoxicillin/clavulanic acid; Ampicillin/Sul, Ampicillin/ sulbactam; Piperacillin/Taz, Piperacillin/tazobactam; Ticarcillin/Cla, Ticarcillin/clavulanic acid; TMP-SMX, trimethoprim-sulfamethoxazole; ESBL, extended-spectrum $\beta$-lactamase.

중 32기관, Pheonix 장비(Becton Dickinson, Sparks, MD, $\mathrm{USA}$ )를 사용했다고 답한 5 기관 중 2기관이 meropenem 감수 성으로 보고하였고, 이들 감수성으로 보고한 기관들 중 Vitek 사용기관 모두와 MicroScan 사용기관 5곳, Pheonix 사용기관 2 곳은 $\mathrm{MIC}$ 를 $4 \mu \mathrm{g} / \mathrm{mL}$ 로 입력했음에도 $\mathrm{S}$ 로 보고하여 개정 전 의 기준으로 판독한 것이 부적절한 답변의 원인이었다(Table 4).

M1412 S. pneumoniae에서 clindamycin 내성이 MIC법 과 디스크확산법 모두 $84 \%$ 에 불과했지만, 디스크확산법으 로 확인했을 때 억제대가 $6 \mathrm{~mm}$ 로 내성이 확실하였고, MIC
법에서 감수성으로 보고한 기관들 모두 MicroScan 사용기 관으로 MICroSTREP 사용기관 22곳 중 20기관이 감수성으 로 보고하여 이 패널의 very major error로 판단하였다. Trimethoprim/sulfamethoxazole은 일치율이 낮아서 판정할 수 없었다. Penicillin 감수성결과를 보고하지 않거나 oxacillin 선 별검사도 실시하지 않은 기관은 부적절한 검사를 한 것으로 평 가했으며 oxacillin R로 보고하면 penicillin MIC를 실시해야 S, $\mathrm{I}, \mathrm{R}$ 로 감별할 수 있어서 $\mathrm{R}$ 로 보고한 2기관 또한 부적절하다고 평가하였다(Table 5). 


\section{Journal of LABORATORY MEDICINE and QUALITY ASSURANCE}

Young Jin Ko et al • Annual EQA for Clinical Microbiology 2014

Table 6. Performance of antimicrobial susceptibility test of M1412-B Streptococcus agalactiae

\begin{tabular}{|c|c|c|c|c|c|c|c|c|c|c|c|c|}
\hline \multirow{2}{*}{ Antimicrobials } & \multicolumn{6}{|c|}{ Disk diffusion method } & \multicolumn{6}{|c|}{ Commercial broth dilution method } \\
\hline & No. lab & $S$ & I & $\mathrm{R}$ & Criteria & $\%$ & No. lab & $S$ & I & $\mathrm{R}$ & Criteria & $\%$ \\
\hline Amikacin & 1 & & & 1 & IA & & & & & & & \\
\hline Amoxicillin/Cla & 1 & 1 & & & IA & & 2 & 2 & & & IA & \\
\hline Ampicillin & 12 & 10 & & 2 & $\mathrm{~S}$ & 83.3 & 34 & 34 & & & S & 100.0 \\
\hline Ampicillin/Sul & & & & & & & 1 & 1 & & & IA & \\
\hline Azithromycin & 1 & 1 & & & & & 1 & 1 & & & & \\
\hline Cefazolin & 2 & 2 & & & IA & & & & & & & \\
\hline Cefepime & 2 & 2 & & & & & 5 & 5 & & & & \\
\hline Cefoperazone & 1 & 1 & & & & & & & & & & \\
\hline Cefotaxime & 11 & 9 & 1 & 1 & S & 81.8 & 24 & 24 & & & S & 100.0 \\
\hline Cefotetan & 1 & 1 & & & IA & & & & & & & \\
\hline Ceftazidime & 2 & 2 & & & IA & & & & & & & \\
\hline Ceftriaxone & 8 & 7 & & 1 & S & 87.5 & 18 & 18 & & & S & 100.0 \\
\hline Cephalothin & 2 & 2 & & & IA & & & & & & & \\
\hline Chloramphenicol & 3 & 3 & & & & & 5 & 4 & 1 & & & \\
\hline Ciprofloxacin & 3 & & & 3 & IA & & 1 & & & 1 & IA & \\
\hline Clindamycin & 20 & 19 & & 1 & $\mathrm{~S}$ & 95.0 & 38 & 37 & & 1 & S & 97.4 \\
\hline Daptomycin & & & & & MIC & & 1 & 1 & & & & \\
\hline Doxycycline & 1 & 1 & & & IA & & & & & & & \\
\hline Erythromycin & 19 & 19 & & & S & 100.0 & 36 & 36 & & & S & 100.0 \\
\hline Gentamicin & 2 & & & 2 & IA & & & & & & & \\
\hline Gentamicin-H & 1 & & & 1 & IA & & & & & & & \\
\hline Imipenem & 1 & 1 & & & IA & & & & & & & \\
\hline Kanamycin & 1 & & & 1 & IA & & & & & & & \\
\hline Levofloxacin & 7 & & & 7 & $\mathrm{R}$ & 100.0 & 30 & & & 30 & $\mathrm{R}$ & 100.0 \\
\hline Linezolid & 1 & 1 & & & $\mathrm{~S}$ & 100.0 & 29 & 29 & & & S & 100.0 \\
\hline Meropenem & 1 & 1 & & & MIC & & & & & & & \\
\hline Netilmicin & 1 & & & 1 & IA & & & & & & & \\
\hline Ofloxacin & & & & & & & 3 & & & 3 & & \\
\hline Oxacillin & 2 & 2 & & & & & 1 & & & 1 & IA & \\
\hline Penicillin G & 13 & 12 & & 1 & S & 92.3 & 29 & 29 & & & S & 100.0 \\
\hline Quinupristin/Dal & & & & & & & 7 & 7 & & & & \\
\hline Tetracycline & 4 & 4 & & & S & 100.0 & 12 & 11 & & 1 & S & 91.7 \\
\hline TMP-SMX & 3 & 1 & & 2 & IA & & 6 & 6 & & & IA & \\
\hline Vancomycin & 21 & 20 & 1 & & $S$ & 95.2 & 38 & 38 & & & $S$ & 100.0 \\
\hline ICR & 6 & 6 & & & & & & & & & & \\
\hline
\end{tabular}

Abbreviations: S, susceptible; I, intermediate; R, resistance; Amoxicillin/Cla, Amoxicillin/clavulanic acid; Ampicillin/Sul, Ampicillin/ sulbactam; Piperacillin/Taz, Piperacillin/tazobactam; Ticarcillin/Cla, Ticarcillin/clavulanic acid; TMP-SMX, trimethoprim-sulfamethoxazole; ESBL, extended-spectrum $\beta$-lactamase; ICR, inducible clindamycin resistance; Gentamicin-H, high level resistance to gentamicin; Quinupristin/Dal, Quinupristin/dalfopristin. 


\section{Journal of LABORATORY MEDICINE and QUALITY ASSURANCE}

Young Jin Ko et al • Annual EQA for Clinical Microbiology 2014

Table 7. Performance of antimicrobial susceptibility test of M1421 Staphylococcus aureus

\begin{tabular}{|c|c|c|c|c|c|c|c|c|c|c|c|c|}
\hline \multirow{2}{*}{ Antimicrobials } & \multicolumn{6}{|c|}{ Disk diffusion method } & \multicolumn{6}{|c|}{ Commercial broth dilution method } \\
\hline & No. lab & $S$ & I & $\mathrm{R}$ & Criteria & $\%$ & No. lab & $\mathrm{S}$ & I & $\mathrm{R}$ & Criteria & $\%$ \\
\hline Amikacin & 1 & & 1 & & & & & & & & & \\
\hline Amoxicillin/Cla & 2 & & & 2 & & & 1 & & & 1 & & \\
\hline Ampicillin & 6 & & & 6 & & & 4 & & & 4 & & \\
\hline Azithromycin & 1 & & & 1 & $\mathrm{R}$ & 100.0 & 13 & & & 13 & $\mathrm{R}$ & 100.0 \\
\hline Cefazolin & 3 & & & 3 & IA & & 1 & & & 1 & IA & \\
\hline Cefepime & & & & & & & 1 & & & 1 & IA & \\
\hline Cefmetazole & 1 & & & 1 & IA & & & & & & & \\
\hline Cefotaxime & 3 & & & 3 & IA & & 1 & & & 1 & IA & \\
\hline Cefotetan & 1 & & & 1 & IA & & & & & & & \\
\hline Cefoxitin & 5 & & & 5 & $\mathrm{R}$ & 100.0 & 1 & & & 1 & $\mathrm{R}$ & 100.0 \\
\hline Ceftazidime & 1 & & & 1 & IA & & & & & & & \\
\hline Ceftriaxone & 6 & & & 6 & IA & & & & & & & \\
\hline Cefuroxime & 2 & & & 2 & IA & & & & & & & \\
\hline Cephalothin & 3 & & & 3 & IA & & & & & & & \\
\hline Chloramphenicol & 5 & 5 & & & & & 3 & 3 & & & & \\
\hline Ciprofloxacin & 26 & & & 26 & $\mathrm{R}$ & 100.0 & 125 & & & 125 & $\mathrm{R}$ & 100.0 \\
\hline Clarithromycin & 2 & & & 2 & & & & & & & & \\
\hline Clindamycin & 33 & & & 33 & $\mathrm{R}$ & 100.0 & 218 & & & 218 & $\mathrm{R}$ & 100.0 \\
\hline Daptomycin & & & & & & & 17 & 17 & & & S & 100.0 \\
\hline Doxycycline & 2 & & & 2 & & & & & & & & \\
\hline Erythromycin & 30 & & & 30 & $\mathrm{R}$ & 100.0 & 215 & & & 215 & $\mathrm{R}$ & 100.0 \\
\hline Fosfomycin & & & & & & & 1 & 1 & & & & \\
\hline Fusidic Acid & & & & & & & 1 & & & 1 & & \\
\hline Gentamicin & 22 & & & 22 & $\mathrm{R}$ & 100.0 & 97 & & & 97 & $\mathrm{R}$ & 100.0 \\
\hline Imipenem & 5 & & & 5 & IA & & & & & & & \\
\hline Levofloxacin & 4 & & & 4 & & & 2 & & & 2 & & \\
\hline Linezolid & 5 & 5 & & & S & 100.0 & 194 & 194 & & & S & 100.0 \\
\hline Meropenem & 2 & & & 2 & IA & & & & & & & \\
\hline Mupirocin & & & & & & & 4 & 4 & & & & \\
\hline Nitrofurantoin & & & & & & & 2 & 2 & & & Urine only & \\
\hline Ofloxacin & & & & & & & 1 & & & 1 & & \\
\hline Oxacillin & 35 & & & 35 & MIC only & & 219 & & & 219 & $\mathrm{R}$ & 100.0 \\
\hline Penicillin G & 30 & & & 30 & $\mathrm{R}$ & 100.0 & 200 & & & 200 & $\mathrm{R}$ & 100.0 \\
\hline Piperacillin/Taz & 1 & & & 1 & & & & & & & & \\
\hline Quinupristin/Dal & & & & & & & 7 & 7 & & & & \\
\hline Rifampin & 5 & 5 & & & $S$ & 100.0 & 151 & 151 & & & $S$ & 100.0 \\
\hline Teicoplanin & 12 & 11 & 1 & & S & 91.7 & 40 & 40 & & & S & 100.0 \\
\hline Telithromycin & & & & & & & 13 & & & 13 & $\mathrm{R}$ & 100.0 \\
\hline Tetracycline & 14 & & & 14 & $\mathrm{R}$ & 100.0 & 188 & & & 188 & $\mathrm{R}$ & 100.0 \\
\hline Tigecycline & & & & & & & 3 & 1 & & 2 & IA & \\
\hline TMP-SMX & 31 & 31 & & & S & 100.0 & 212 & 212 & & & $S$ & 100.0 \\
\hline Vancomycin & 22 & 21 & & 1 & MIC only & & 224 & 223 & & 1 & $S$ & 100.0 \\
\hline
\end{tabular}

Abbreviations: S, susceptible; I, intermediate; R, resistance; Amoxicillin/Cla, Amoxicillin/clavulanic acid; Ampicillin/Sul, Ampicillin/ sulbactam; Piperacillin/Taz, Piperacillin/tazobactam; Ticarcillin/Cla, Ticarcillin/clavulanic acid; TMP-SMX, trimethoprim-sulfamethoxazole; ESBL, extended-spectrum $\beta$-lactamase; ICR, inducible clindamycin resistance; Gentamicin-H, high level resistance to gentamicin; Quinupristin/Dal, Quinupristin/dalfopristin. 


\section{Journal of LABORATORY MEDICINE and QUALITY ASSURANCE}

\section{Young Jin Ko et al • Annual EQA for Clinical Microbiology 2014}

Table 8. Performance of antimicrobial susceptibility test of M1422-A, B Salmonella spp. serogroup C

\begin{tabular}{|c|c|c|c|c|c|c|c|c|c|c|c|c|}
\hline \multirow{2}{*}{ Antimicrobials } & \multicolumn{6}{|c|}{ Disk diffusion method } & \multicolumn{6}{|c|}{ Commercial broth dilution method } \\
\hline & No. lab & $S$ & I & $\mathrm{R}$ & Criteria & $\%$ & No. lab & $S$ & I & $\mathrm{R}$ & Criteria & $\%$ \\
\hline Amikacin & 10 & 9 & & 1 & IA & & 10 & 1 & & 9 & IA & \\
\hline Ampicillin & 26 & & & 26 & $\mathrm{R}$ & 100.0 & 151 & & & 151 & $\mathrm{R}$ & 100.0 \\
\hline Ampicillin/Sul & 3 & 3 & & & IA & & 5 & & 2 & 3 & IA & \\
\hline Cefaclor & 1 & 1 & & & IA & & & & & & IA & \\
\hline Cefazolin & 2 & 2 & & & IA & & 11 & 2 & & 9 & IA & \\
\hline Cefepime & 3 & 3 & & & S & 100.0 & 37 & 37 & & & S & 100.0 \\
\hline Cefoperazone & & & & & & & 1 & 1 & & & IA & \\
\hline Ceftriaxone & 6 & 6 & & & S & 100.0 & 9 & 9 & & & S & 100.0 \\
\hline Chloramphenicol & 7 & & & 7 & $\mathrm{R}$ & 100.0 & 5 & & & 5 & $\mathrm{R}$ & 100.0 \\
\hline Ciprofloxacin & 42 & 18 & 23 & 1 & $\mathrm{I}, \mathrm{S}$ & 97.6 & 123 & 49 & 53 & 21 & I, S & 82.9 \\
\hline Doxycycline & 1 & & & 1 & IA & & & & & & IA & \\
\hline Ertapenem & & & & & & & 14 & 14 & & & IA & \\
\hline Gentamicin & 7 & 7 & & & IA & & 13 & 2 & & 11 & IA & \\
\hline Imipenem & 10 & 10 & & & IA & & 24 & 24 & & & IA & \\
\hline Levofloxacin & 3 & 3 & & & S & 100.0 & 15 & 10 & 4 & 1 & $\mathrm{I}, \mathrm{S}$ & 93.3 \\
\hline Meropenem & 2 & 2 & & & IA & & 8 & 8 & & & IA & \\
\hline Ticarcillin/Cla & & & & & & & 1 & 1 & & & IA & \\
\hline Tigecycline & & & & & & & 5 & 5 & & & IA & \\
\hline Tobramycin & 3 & 3 & & & IA & & 1 & 1 & & & IA & \\
\hline TMP-SMX & 22 & 1 & & 21 & $\mathrm{R}$ & 95.5 & 152 & & & 152 & $\mathrm{R}$ & 100.0 \\
\hline
\end{tabular}

Abbreviations: S, susceptible; I, intermediate; R, resistance; Amoxicillin/Cla, Amoxicillin/clavulanic acid; Ampicillin/Sul, Ampicillin/ sulbactam; Piperacillin/Taz, Piperacillin/tazobactam; Ticarcillin/Cla, Ticarcillin/clavulanic acid; TMP-SMX, trimethoprim-sulfamethoxazole; ESBL, extended-spectrum $\beta$-lactamase.

M1412에 포함된 S. agalactiae는 levofloxacin 내성이 있 는 균주로서 $\mathrm{MIC}$ 법을 사용하는 기관들은 모든 항균제에 매 우 높은 정답률을 보여준 데 비해 디스크확산법을 사용한 기 관들은 $\beta$-lactam계 항균제에 내성을 보고한 경우가 있어서 ampicillin, cefotaxime, ceftriaxone 정답률이 $80 \%$ 대에 불과 하였다(Table 6).
M1421 Staphylococcus aureus 균주는 methicillinresistant S. aureus (MRSA)의 전형적인 다제내성 균으로 서 높은 정답률을 보였지만, 가장 빈번한 부적절한 결과의 요 인은 보고할 항균제 선택이었다. 디스크확산법으로 검사하는 기관들 중 cephalosporin, imipenem, meropenem 보고한 곳 이 1-6곳, oxacillin과 vancomycin은 35,22 곳에 달했다. MIC 
Journal of LABORATORY MEDICINE and QUALITY ASSURANCE

Young Jin Ko et al • Annual EQA for Clinical Microbiology 2014

Table 9. Performance of antimicrobial susceptibility test of M1422-C Salmonella spp. serogroup D

\begin{tabular}{|c|c|c|c|c|c|c|c|c|c|c|c|c|}
\hline \multirow{2}{*}{ Antimicrobials } & \multicolumn{6}{|c|}{ Disk diffusion method } & \multicolumn{6}{|c|}{ Commercial broth dilution method } \\
\hline & No. lab & $\mathrm{S}$ & $\mathrm{I}$ & $\mathrm{R}$ & Criteria & $\%$ & No. lab & $S$ & $\mathrm{I}$ & $\mathrm{R}$ & Criteria & $\%$ \\
\hline Amikacin & 3 & 3 & & & IA & & 5 & 1 & & 4 & IA & \\
\hline Amoxicillin/Cla & 1 & 1 & & & IA & & 9 & 9 & & & IA & \\
\hline Ampicillin & 6 & 1 & & 5 & $\mathrm{R}$ & 83.3 & 48 & & & 48 & $\mathrm{R}$ & 100.0 \\
\hline Ampicillin/Sul & & & & & IA & & 1 & & & 1 & IA & \\
\hline Aztreonam & 2 & 1 & & 1 & & & 2 & & & 2 & & \\
\hline Carbenicillin & 1 & & & 1 & IA & & & & & & IA & \\
\hline Cefazolin & & & & & IA & & 7 & & & 7 & IA & \\
\hline Cefepime & & & & & $\mathrm{R}$ & & 12 & & & 12 & $\mathrm{R}$ & 100 \\
\hline Cefoperazone & 1 & 1 & & & IA & & & & & & IA & \\
\hline Cefotaxime & 2 & & & 2 & $\mathrm{R}$ & 100.0 & 43 & & & 43 & $\mathrm{R}$ & 100.0 \\
\hline Cefoxitin & & & & & IA & & 2 & 1 & & 1 & IA & \\
\hline Ceftazidime & 4 & 2 & 1 & 1 & $\mathrm{R}$ & 25.0 & 39 & & & 39 & $\mathrm{R}$ & 100.0 \\
\hline Ceftriaxone & 3 & 1 & & 2 & & & 4 & & & 4 & & \\
\hline Cephalothin & 2 & 1 & & 1 & IA & & & & & & IA & \\
\hline Chloramphenicol & 3 & 3 & & & & & 1 & 1 & & & & \\
\hline Ciprofloxacin & 12 & 4 & 8 & & S, I & 100.0 & 37 & 26 & 11 & & S, I & 100.0 \\
\hline Ertapenem & & & & & IA & & 2 & 2 & & & IA & \\
\hline Gentamicin & 4 & 2 & & 2 & IA & & 7 & & & 7 & IA & \\
\hline Imipenem & 2 & 2 & & & IA & & 8 & 8 & & & IA & \\
\hline Levofloxacin & & & & & & & 3 & 3 & & & & \\
\hline Meropenem & 1 & 1 & & & IA & & 1 & 1 & & & IA & \\
\hline Nalidixic acid & 1 & & & 1 & & & 1 & & & 1 & & \\
\hline Piperacillin & 1 & 1 & & & IA & & & & & & IA & \\
\hline Piperacillin/Taz & & & & & IA & & 8 & 8 & & & IA & \\
\hline Tobramycin & 1 & 1 & & & IA & & & & & & IA & \\
\hline TMP-SMX & 5 & 3 & 1 & 1 & S & 60.0 & 46 & 46 & & & $\mathrm{~S}$ & 100.0 \\
\hline
\end{tabular}

Abbreviations: S, susceptible; I, intermediate; R, resistance; Amoxicillin/Cla, Amoxicillin/clavulanic acid; Ampicillin/Sul, Ampicillin/sulbactam; Piperacillin/Taz, Piperacillin/tazobactam; Ticarcillin/Cla, Ticarcillin/clavulanic acid; TMP-SMX, trimethoprim-sulfamethoxazole; ESBL, extended-spectrum $\beta$-lactamase.

법 사용 기관 중에는 소변 검체에 대해서만 보고해야 하는 nitrofurantoin 감수성 검사를 보고한 2곳과 tigecycline 감수 성 검사를 보고한 3곳은 부적절한 평가를 받았다. S. aureus 에서 베타락탐 항균제에 대한 감수성 검사로서 꼭 필요한 penicillin, oxacillin 감수성 검사를 보고하지 않거나 MRSA에 서 필수적으로 검사해야 할 vancomycin 감수성 검사를 누락 한 $31,7,15$ 곳은 이로 인해 부적절 평가를 받았다(Table 7).

M1422 Salmonella serogroup C (A, B set)/Salmonella serogroup D (C set) 중 group C 균주는 ampicillin 내성, group D 균주는 ampicillin과 3, 4세대 cephalosporin까지 내
성이었는데 이들 항균제 감수성 검사는 높은 정답률을 보였 다. Ciprofloxacin 감수성 검사는 불일치율이 높았다(Tables 8, 9). Group C 균주는 디스크억제대가 $30 \mathrm{~mm}$, ciprofloxacin Etest MIC $0.38 \mu \mathrm{g} / \mathrm{mL}$ 이고, group D 균주는 디스크억제 대가 $28 \mathrm{~mm}$, ciprofloxacin Etest MIC $0.19 \mu \mathrm{g} / \mathrm{mL}$ 로 둘 다 intermediate 범위에 해당한다. 하지만 nalidixic acid가 group $\mathrm{C}$ 는 $\leq 16 \mu \mathrm{g} / \mathrm{mL}, 19 \mathrm{~mm}$ 인데 비해 group $\mathrm{D}$ 는 $\geq 32$ $\mu \mathrm{g} / \mathrm{mL}, 6 \mathrm{~mm}$ 로 큰 차이를 보였다(Fig. 2). 둘 다 MicroScan $\mathrm{NC} 72$ 는 $\leq 1 \mu \mathrm{g} / \mathrm{mL}$, MIC 패널인 NM44에서는 $\leq 0.5 \mu \mathrm{g} / \mathrm{mL}$ 로 intermediate를 포함하는 결과를 보이는 반면, Vitek $2 \mathrm{GN}$ 

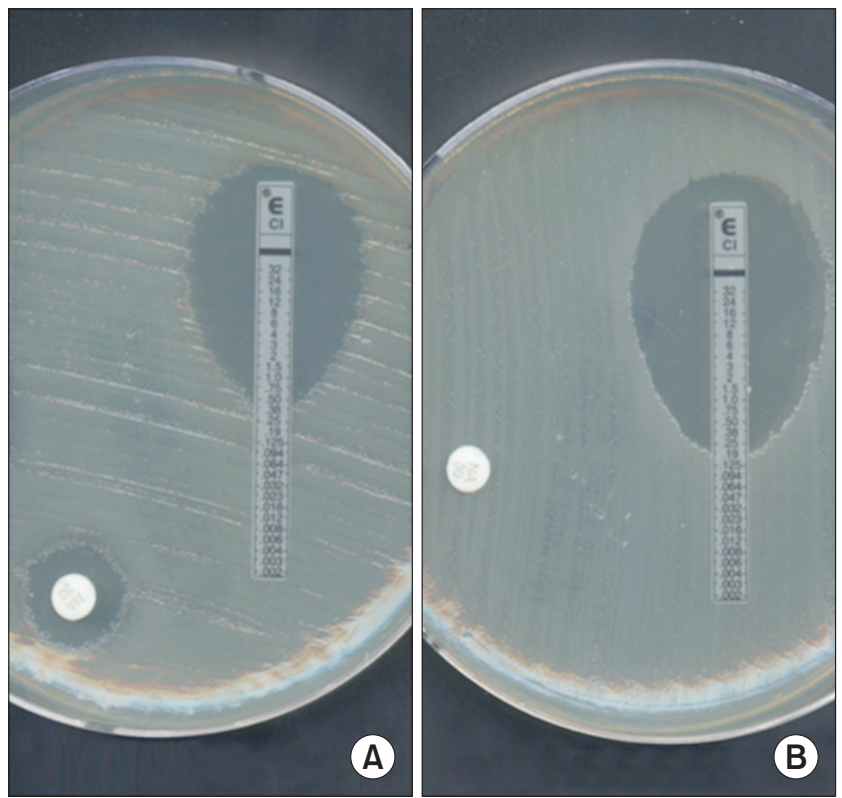

Fig. 2. The results of nalidixic acid disk diffusion test and ciprofloxacin Etest of M1422 Salmonella (A) group C and (B) group D strains.

카드에서 group C 균주는 0.12-0.5, $1,2 \mu \mathrm{g} / \mathrm{mL}$ 등 다양한 결 과를 보여 $25,47,16$ 곳이 S, I, R로 답했다. 이에 비해 디스크 확산법 사용자들은 $17,23,1$ 곳이 S, I, R로 답해서, I, S를 정 답으로 처리하였다. Group D 균주는 디스크확산법과 MIC 검 사자 $100.0 \%$ 가 S, I로 답해서 이를 정답으로 처리하였다. 하 지만 MicroScan 사용자는 MIC가 $\leq 1 \mu \mathrm{g} / \mathrm{mL}$ 로 모두 S라고 답한 반면, Vitek 사용자는 $012-0.5 \mu \mathrm{g} / \mathrm{mL}$ 의 값을 보이고, 15 곳이 S, 8곳이 I라고 답했습니다. 디스크확산법에서 21-30 $\mathrm{mm}$ 결과를 많은 기관에서 $\mathrm{S}$ 로 판독하였고, $12 \mathrm{~mm}$ 를 $\mathrm{S}$ 라고 답한 곳도 1 기관이 있는 등 Salmonella의 fluoroquinolone 감 수성 판독에 오류가 많았다.

\section{4. 특수세균배양 및 동정}

특수세균으로 S1401 그람양성 막대균인 Erysipelothrix rhusiopathiae, S1402 혐기성세균인 Finegoldia magna의 종 수준 동정률은 91.4\%, 89.7\%이었고, S1403 Scedosporidium apiospermum, S1404 Actinomyces odontolyticus는 종수 준 동정률은 낮았으나 속수준은 90.5\%, 93.7\% 정도였다. Scedosporidium apiospermum는 Scedosporidium 속으 로 보고한 기관이 $33 \%$ 인데 기인했지만, A. odontolyticus는 Actinomyces meyeri나 Actinomyces naeslundii로 오동정하 는 기관이 $41 \%$ 로 많았고 이는 Vitek2 동정결과였다. S1405

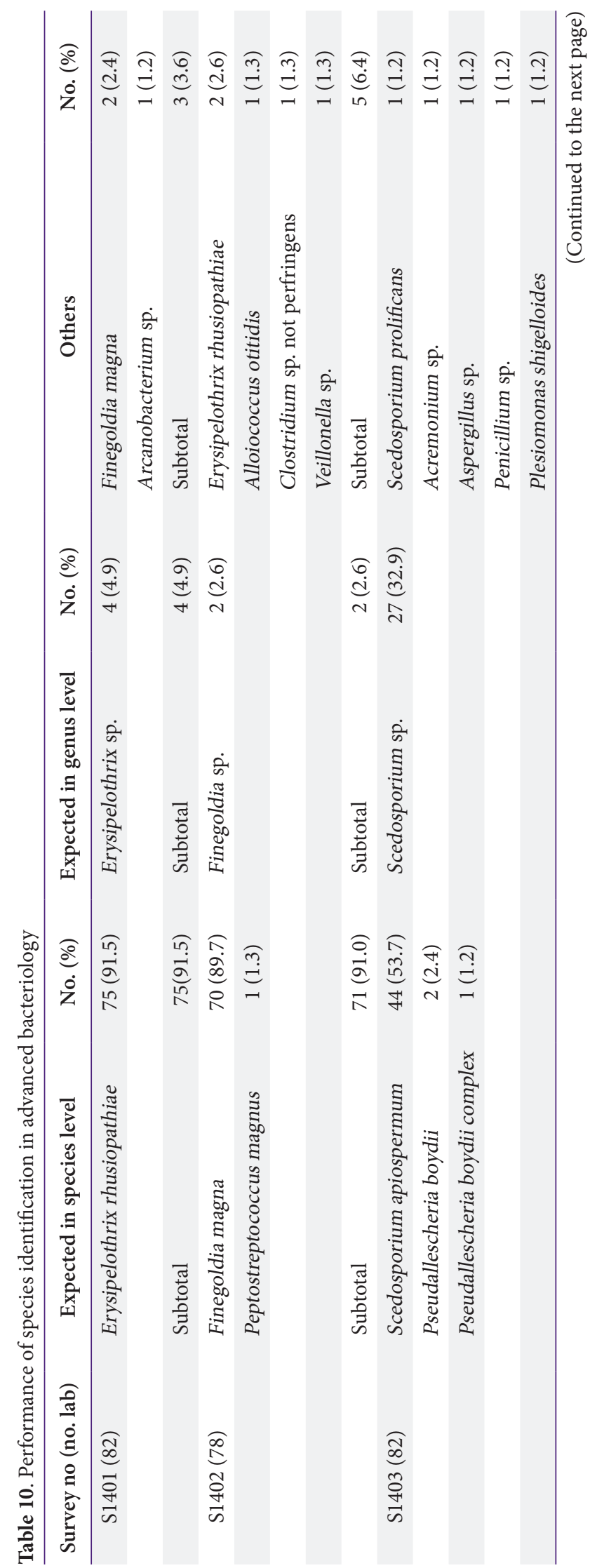


Journal of LABORATORY MEDICINE and QUALITY ASSURANCE

Young Jin Ko et al • Annual EQA for Clinical Microbiology 2014

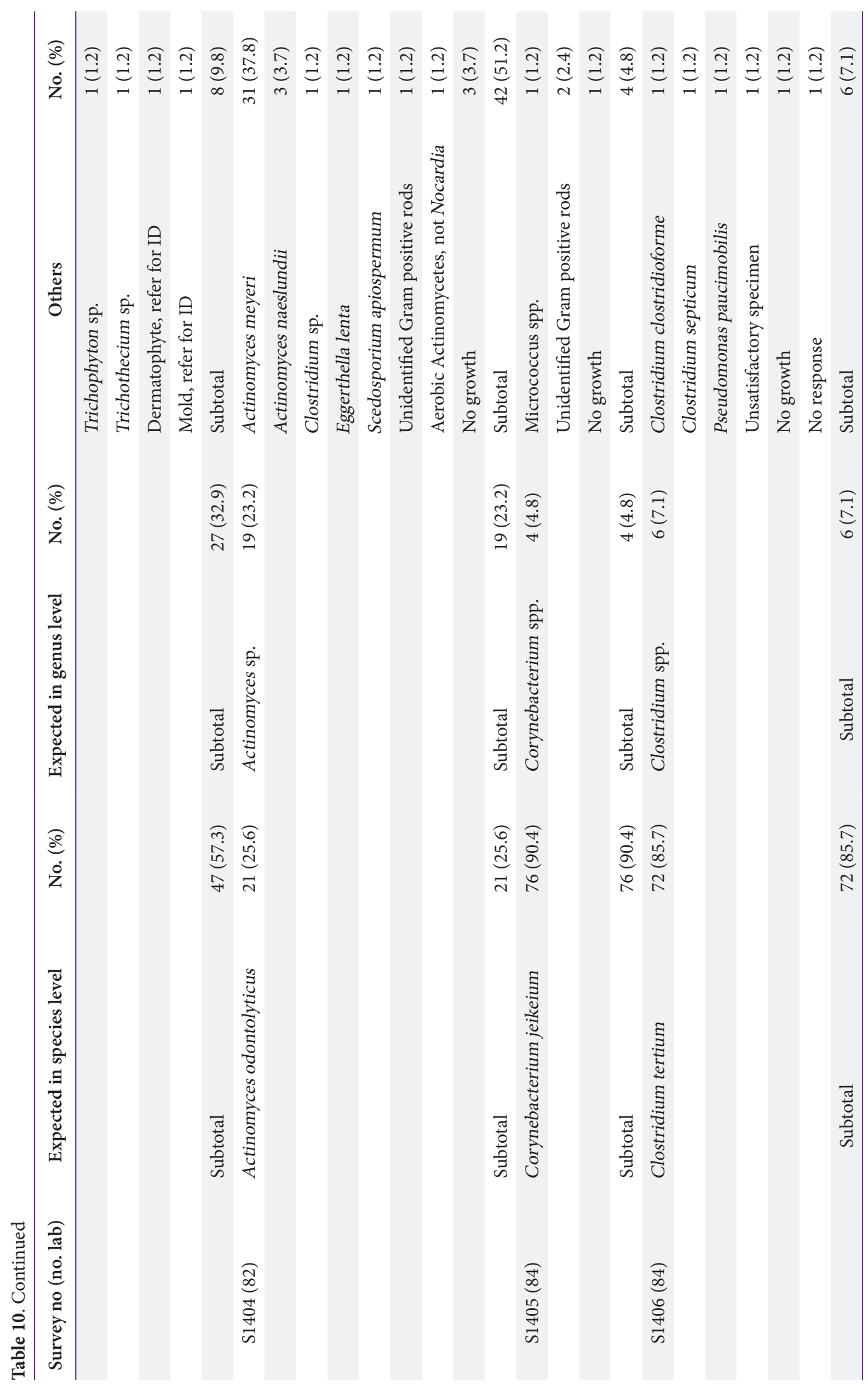




\section{Journal of LABORATORY MEDICINE and QUALITY ASSURANCE}

Young Jin Ko et al • Annual EQA for Clinical Microbiology 2014

Table 11. Performance of species identification in mycobacteriology

\begin{tabular}{|c|c|c|c|c|c|c|}
\hline $\begin{array}{l}\text { Survey no. } \\
\text { (no. lab) }\end{array}$ & Good & No. $(\%)$ & Acceptable & No. $(\%)$ & Not acceptable & No. (\%) \\
\hline \multirow[t]{3}{*}{ T1401 (79) } & Mycobacterium kansasii & $16(20.3)$ & $\begin{array}{l}\text { Mycobacterium other } \\
\text { than } M \text {. tuberculosis } \\
\text { complex }\end{array}$ & $55(69.6)$ & $\begin{array}{l}\text { Nonphotochromogen (not } M \text {. } \\
\text { tuberculosis), refer for ID }\end{array}$ & $3(3.8)$ \\
\hline & & & & & Rapid grower, refer for ID & $1(1.3)$ \\
\hline & & & & & No response & $4(5.1)$ \\
\hline \multirow[t]{2}{*}{ T1402 (79) } & $\begin{array}{l}\text { Mycobacterium tuberculosis } \\
\text { complex }\end{array}$ & $68(86.1)$ & & & Negative for Mycobacteria & $2(2.5)$ \\
\hline & $\begin{array}{l}\text { Mycobacterium tuberculosis } \\
\text { (not } M . \text { africanum, } M . \\
\text { bovis, or M. microti) }\end{array}$ & $6(7.6)$ & & & No response & $3(3.8)$ \\
\hline \multirow{2}{*}{ T1403 (79) } & $\begin{array}{l}\text { Mycobacterium tuberculosis } \\
\text { (not } M . \text { africanum, } M \text {. } \\
\text { bovis, or } M . \text { microti) }\end{array}$ & $6(7.6)$ & & & No response & $4(5.1)$ \\
\hline & Subtotal & $71(89.9)$ & Subtotal & 0 & Subtotal & $8(10.1)$ \\
\hline \multirow[t]{3}{*}{ T1404 (79) } & Negative for Mycobacteria & $73(92.4)$ & & & $\begin{array}{l}\text { Mycobacterium other than } \\
\text { M. tuberculosis }\end{array}$ & $1(1.3)$ \\
\hline & & & & & $\begin{array}{l}\text { Mycobacterium intracellulare } \\
\quad(\operatorname{not} M . \text { avium })\end{array}$ & $1(1.3)$ \\
\hline & & & & & No response & $4(5.1)$ \\
\hline \multirow{2}{*}{ T1405 (79) } & & & $\begin{array}{l}\text { Mycobacterium } \\
\text { nonchromogenicum } \\
\text { (not } M . \text { terrae or } M . \\
\text { triviale) }\end{array}$ & $1(1.3)$ & & \\
\hline & Subtotal & $15(19.0)$ & Subtotal & $58(73.4)$ & Subtotal & $6(7.6)$ \\
\hline \multirow[t]{4}{*}{$\mathrm{T} 1411(81)$} & $\begin{array}{l}\text { Mycobacterium tuberculosis } \\
\text { complex }\end{array}$ & $68(84.0)$ & $\begin{array}{l}\text { Mycobacterium } \\
\text { tuberculosis (not } M \text {. } \\
\text { africanum, M. bovis, or } \\
\text { M. microti) }\end{array}$ & $6(7.4)$ & $\begin{array}{l}\text { Mycobacterium other than } M \text {. } \\
\text { tuberculosis complex }\end{array}$ & $2(2.5)$ \\
\hline & & & & & No response & $4(4.9)$ \\
\hline & & & & & Refer for ID & $1(1.2)$ \\
\hline & Subtotal & $68(84.0)$ & Subtotal & $6(7.4)$ & Subtotal & $7(8.6)$ \\
\hline \multirow[t]{2}{*}{$\mathrm{T} 1412(81)$} & Negative for Mycobacteria & $78(96.3)$ & & & No response & $3(3.7)$ \\
\hline & Subtotal & $78(96.3)$ & Subtotal & 0 & Subtotal & $3(3.7)$ \\
\hline
\end{tabular}

(Continued to the next page) 
Journal of LABORATORY MEDICINE and QUALITY ASSURANCE

Young Jin Ko et al • Annual EQA for Clinical Microbiology 2014

Table 11. Continued

\begin{tabular}{|c|c|c|c|c|c|c|}
\hline $\begin{array}{l}\text { Survey no. } \\
\text { (no. lab) }\end{array}$ & Good & No. (\%) & Acceptable & No. (\%) & Not acceptable & No. (\%) \\
\hline \multirow[t]{5}{*}{ T1413 (81) } & Mycobacterium kansasii & $16(19.8)$ & $\begin{array}{l}\text { Mycobacterium other than } \\
\text { M. tuberculosis complex }\end{array}$ & $57(70.4)$ & No response & $4(4.9)$ \\
\hline & & & & & Refer for ID & $1(1.2)$ \\
\hline & & & $\begin{array}{l}\text { Nonphotochromogen } \\
\text { (not } M \text {. tuberculosis), } \\
\text { refer for ID }\end{array}$ & $2(2.5)$ & & \\
\hline & & & $\begin{array}{l}\text { Photochromogen, refer for } \\
\text { ID }\end{array}$ & $1(1.2)$ & & \\
\hline & Subtotal & $16(19.8)$ & Subtotal & $60(74.1)$ & Subtotal & $5(6.1)$ \\
\hline \multirow[t]{5}{*}{$\mathrm{T} 1414(81)$} & $\begin{array}{l}\text { Mycobacterium avium } \\
\quad \text { (not } M . \text { intracellulare) }\end{array}$ & $13(16.0)$ & $\begin{array}{l}\text { Mycobacterium other than } \\
\text { M. tuberculosis complex }\end{array}$ & $57(70.4)$ & No response & $4(4.9)$ \\
\hline & & & $\begin{array}{l}\text { Mycobacterium avium } \\
\text { complex }\end{array}$ & $2(2.5)$ & Refer for ID & $1(1.2)$ \\
\hline & & & $\begin{array}{l}\text { Nonphotochromogen } \\
\text { (not } M \text {. tuberculosis), } \\
\text { refer for ID }\end{array}$ & $3(3.7)$ & & \\
\hline & & & $\begin{array}{l}\text { Mycobacterium } \\
\text { intracellulare } \\
\text { (not } M . \text { avium) }\end{array}$ & $1(1.2)$ & & \\
\hline & Subtotal & $13(16.0)$ & Subtotal & $63(77.8)$ & Subtotal & $5(6.2)$ \\
\hline \multirow[t]{4}{*}{ T1415 (81) } & $\begin{array}{l}\text { Mycobacterium tuberculosis } \\
\text { complex }\end{array}$ & $69(85.2)$ & & & $\begin{array}{l}\text { Mycobacterium other than } \\
\text { M. tuberculosis complex }\end{array}$ & $1(1.2)$ \\
\hline & $\begin{array}{l}\text { Mycobacterium tuberculosis } \\
\text { (not } M . \text { africanum, } \\
\text { M. bovis, or M. microti) }\end{array}$ & $6(7.4)$ & & & No response & $4(4.9)$ \\
\hline & & & & & Refer for ID & $1(1.2)$ \\
\hline & Subtotal & $75(92.6)$ & Subtotal & 0 & Subtotal & $6(7.4)$ \\
\hline
\end{tabular}

Corynebacterium jeikeium, S1406 Clostridium tertium 동 정은 각각 $90.5 \%, 85.7 \%$ 의 종수준 정확도를 보였다(Table 10).

\section{5. 항산균배양 동정, 항결핵제 감수성 검사, 결핵 신속내성 검사}

T1402와 T1403은 Mycobacterium tuberculosis HR37Ra 주를 농도를 달리해서 제조한 검체로 농도가 높았던 T1402는 2기관, 낮았던 T1403은 4기관에서 배양음성으로 보고하였다. 동정결과의 Acceptable\%는 94.7-100.0\%로 높았으며, T1401 M. kansasii를 결핵균으로 잘못 동정하거나 T1402, T1403 M. tuberculosis을 비결핵항산균으로 잘못 동정한 기관은 없었다.
단 T1401 M. kansasii를 nonchromogenic, rapid grower로 판독한 것과 T1405의 M. intracellulare를 대표적인 오염균 인 scotochromogen으로 보고한 기관은 부적절하다고 판정하 였다(Table 11). 2차 T1411-T1415에서 항산균 배양에 실패한 기관은 없었고, 항산균 음성인 T1412 검체에서 항산균이 자랐 다고 보고한 기관도 없었다. T1411 M. tuberculosis complex 가 아닌 항산균으로 보고한 2기관만을 동정실패로 평가하여 전반적으로 매우 우수한 동정능을 보였다(Table 11).

항결핵제 감수성 검사에서 T1417 ofloxacin, levofloxacin, T1418 levofloxacin, T1419 moxifloxacin 내성 검출에 실패한 기관이 1곳씩 있었다. Pyrazinamide 검사에서 T1418 위내성 


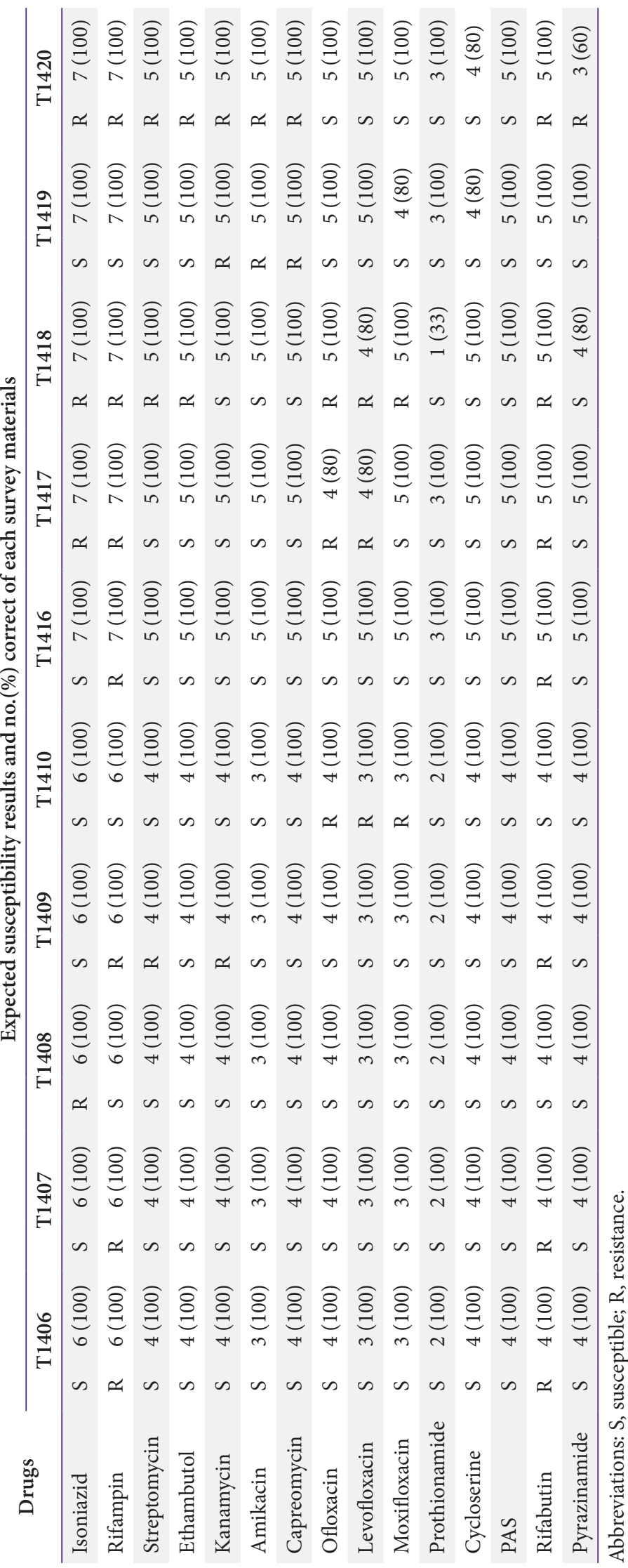


Journal of LABORATORY MEDICINE and QUALITY ASSURANCE

Young Jin Ko et al • Annual EQA for Clinical Microbiology 2014

Table 13. Rapid detection of rifampin and isoniazid resistance

\begin{tabular}{|c|c|c|c|c|c|c|c|c|}
\hline \multirow[b]{2}{*}{ Drugs mutations } & \multicolumn{2}{|c|}{$\mathrm{R} 1401$} & \multicolumn{2}{|c|}{$\mathrm{R} 1402$} & \multicolumn{2}{|c|}{$\mathrm{R} 1403$} & \multicolumn{2}{|c|}{ R1404 } \\
\hline & Expected & $\begin{array}{l}\text { No. (\%) } \\
\text { correct }\end{array}$ & Expected & $\begin{array}{l}\text { No. }(\%) \\
\text { correct }\end{array}$ & Expected & $\begin{array}{l}\text { No. (\%) } \\
\text { correct }\end{array}$ & Expected & $\begin{array}{l}\text { No. (\%) } \\
\text { correct }\end{array}$ \\
\hline \multirow[t]{2}{*}{ rpoB mutation } & & & & & S531L & $19(79)$ & H526T & $18(75)$ \\
\hline & & & & & No response & $5(21)$ & No response & $6(25)$ \\
\hline \multirow[t]{2}{*}{ kat $G$ mutation } & S315T & $20(100)$ & S & $20(100)$ & $\mathrm{S} 315 \mathrm{~T}$ & $17(89)$ & S & $19(100)$ \\
\hline & & & & & No response & $2(11)$ & & \\
\hline inh mutation & S & $19(100)$ & S & $19(100)$ & S & $19(100)$ & S & $20(100)$ \\
\hline
\end{tabular}

Abbreviations: S, susceptible; R, resistance.

Table 14. Performance of microscopic examination of stool preparation in parasitology

\begin{tabular}{|c|c|c|c|c|c|c|}
\hline $\begin{array}{l}\text { Survey no. } \\
\text { (no. lab) }\end{array}$ & Good & No. $(\%)$ & Acceptable & No. (\%) & Not acceptable & No. (\%) \\
\hline \multirow[t]{5}{*}{ P1401 (102) } & Hook worm eggs & $87(85.3)$ & $\begin{array}{l}\text { Hookworm } \\
\text { larvae }\end{array}$ & $2(2.0)$ & Ascaris sp. eggs & $6(5.9)$ \\
\hline & & & & & Trichostrongylus eggs & $4(3.9)$ \\
\hline & & & & & Diphyllobothrium sp. eggs & $2(2.0)$ \\
\hline & & & & & No parasite seen & $1(1.0)$ \\
\hline & Subtotal & $87(85.3)$ & Subtotal & $2(2.0)$ & Subtotal & $4(12.7)$ \\
\hline \multirow[t]{2}{*}{ P1402 (102) } & Trichuris trichiura & $102(100.0)$ & & & & \\
\hline & Subtotal & $102(100.0)$ & Subtotal & 0 & Subtotal & 0 \\
\hline \multirow[t]{8}{*}{ P1403 (98) } & No parasite seen & $70(71.4)$ & & & Entamoeba coli & $15(15.3)$ \\
\hline & & & & & Ascaris sp. eggs & $6(6.1)$ \\
\hline & & & & & Enterobius vermicularis eggs & $3(3.1)$ \\
\hline & & & & & Clonorchis / Metagonimus eggs & $1(1.0)$ \\
\hline & & & & & Hookworm eggs & $1(1.0)$ \\
\hline & & & & & Paragonimus sp. eggs & $1(1.0)$ \\
\hline & & & & & Trichostrongylus eggs & $1(1.0)$ \\
\hline & Subtotal & $70(71.4)$ & Subtotal & 0 & Subtotal & $28(28.6)$ \\
\hline \multirow[t]{6}{*}{ P1404 (102) } & Giardia intestinalis (lamblia) & $94(92.2)$ & & & Entamoeba histolytica /disper & $3(2.9)$ \\
\hline & & & & & Diphyllobothrium sp. eggs & $1(1.0)$ \\
\hline & & & & & Endolimax nana & $1(1.0)$ \\
\hline & & & & & $\begin{array}{l}\text { Pentatrichomonas (Trichomonas) } \\
\text { hominis }\end{array}$ & $1(1.0)$ \\
\hline & & & & & No parasite seen & $2(2.0)$ \\
\hline & Subtotal & $94(92.2)$ & Subtotal & 0 & Subtotal & $8(7.8)$ \\
\hline \multirow[t]{4}{*}{ P1405 (102) } & Diphyllobothrium sp. eggs & $92(90.2)$ & & & Paragonimus sp. eggs & $7(6.9)$ \\
\hline & & & & & Clonorchis / Metagonimus eggs & $2(2.0)$ \\
\hline & & & & & Fasciola hepatica / Fasciolabuski eggs & $1(1.0)$ \\
\hline & Subtotal & $92(90.2)$ & Subtotal & 0 & Subtotal & $10(9.8)$ \\
\hline
\end{tabular}




\title{
Journal of LABORATORY MEDICINE and QUALITY ASSURANCE
}

\author{
Young Jin Ko et al • Annual EQA for Clinical Microbiology 2014
}

1 곳, T1420 위감수성 2곳이 있었다(Table 12). 결핵균 신속내 성 검사에서 isoniazid와 rifampin 내성 검출 모두 $100.0 \%$ 정 답률을 보였다(Table 13).

\section{6. 기생충검사}

P1401 Hookworm eggs 85.3\%, P1402 Trichuris trichiura 는 100.0\%. Giardia intestinalis 94.2\%, Diphylobothrium latum eggs $90.2 \%$ 의 정답률을 보였는데 기생충이 없었던 $\mathrm{P} 1403$ 의 정답률이 $71.4 \%$ 로 가장 낮았다(Table 14).

\section{7. 연구용 털곰팡이류 배양 및 동정, 카바페네메제 생산 장내세 균 검출}

털곰팡이류 배양 동정검사 신빙도조사에 참여해서 동 정결과를 입력한 기관 중 F1401 Aspergillus terreus, F1402 Aspergillus fumigatus, F1403 Aspergillus flavus, F1404 Trichophyton rubrum, F1405 Trichophyton mentagrophyte 등의 종수준 동정 정확도는 78.5\%, 92.1\%, 82.0\%, $65.6 \%, 48.4 \%$ 로 A. fumigatus의 정확도가 가장 높았고, $\mathrm{Tri}^{-}$ chophyton 종의 동정능은 Aspergillus 종보다 낮았다(Table 15).

카바페네메제생산 장내세균 검출에서 선별 시험인 $\mathrm{MHT}$ 에 $\mathrm{C} 1401$ 위음성이 $7.5 \%, \mathrm{C} 1402, \mathrm{C} 1403$ 의 위양성이 $49.5 \%$, $15.4 \%$ 발생하였다. C1402 AmpC $\beta$-lactamase를 생산하는 E. cloacae를 Klebsiella pneumoniae carbapenemase (KPC) 생산 균주로 보고한 기관이 45곳(63.4\%)에 달했다(Table 16).

\section{고찰}

세균 분야의 회원기관 수나 응답률은 2013년 신빙도조사 때와 유사하였다[7]. 그람음성간균에 대해서는 배양과 동정 검사 수행능이 우수한데 Salmonella 혈청형 검사를 실시하 지 않거나 혈청형 오류가 $20.0 \%$ 를 넘어서 혈청형 검사에 대 한 질 관리가 필요함을 알 수 있었다. 가장 동정 정확도가 떨어 지는 균종은 비교적 흔하지 않은 Candida의 종수준 동정으로 C. glabrata, C. auris는 48.0\%, $1.6 \%$ 에 불과하였다. 특히 C. auris는 표현형적으로나 유전형적으로 Candida haemulonii 와 유사하여 complex를 이루는 균종으로 2009년 일본에서 처 음 외이도에서 분리되어 C. auris로 명명되었다[8]. 국내에 서 만성중이염환자의 이루에서 흔히 분리되는 Candida 종 으로, 분자역학적으로도 $C$. auris의 확산이 클론성인 것으로 보고된 바 있다. 국내 한 대학병원에서 진균혈증 3 예가 보고
될 때 azole 내성으로 인한 치료실패와 치명률을 보였다. 따 라서 이 균종이 임상 검체에서 분리될 때 종동정을 정확히 해 주는 것이 임상적으로 중요하다. 현재 상업화된 동정키트로 는 종수준 동정이 안 되지만, M1414에서 대부분 종수준 동 정이 C. haemoulonii였던 것처럼 Vitek YST 카드에서는 C. haemulonii로 동정되고, API 20에서는 Rhodotorula glutinis 로 동정된다는 것이 실마리가 될 수 있다. C. haemulonii 또 는 R. glutinis로 동정되는 균이 집락성상이 Rhodotorula와 달 리 Candida 종으로 생각되고, fluconazole 내성이 있다면 $C$. auris를 추정할 수 있을 것이다. CHROMagar Candida 배지 에서는 pink colony로 나타나서 C. haemoulonii의 lavender colony와 감별할 수 있다. Vitek YST에서 C. haemulonii로 동정되는 균종은 C. haemulonii complex에 속하는 C.pseudohaemulonii, C. auris 등을 포함하기 때문에 종수준의 신뢰 성은 없고, 현재 정확한 종수준 동정을 위해서는 ITS 부위의 염기서열분석이 필요하다.

2014년에는 특수세균 신빙도조사 참여기관 수가 86기관 으로 증가하였다. 배양과 동정이 까다로운 그람양성 간균으 로 E. rusiopathiae, C. jeikeium, 혐기성세균으로 F. magna, A. odontolyticus, C. tertium, 털곰팡이류로 Scedosporium apiospermum 등을 배양 동정하는 시도를 통해 혐기성 균과 털곰팡이류에 대한 수행능을 평가할 수 있었다. A. odontolyticus는 A. meyeri로 동정하는 오류가 많아서 Actinomyces 종동정에 생화학적 동정방법을 대체하는 동정 방법이 필요하다는 것을 알 수 있다. Matrix-assisted laser desorption ionization-time of flight mass spectrometry는 Actinomyces 등 혐기성균 동정에 유용하게 사용될 수 있을 것 이다[9].

M1402 K. pneumoniae 주의 광범위 세팔로스포린 내성 은 $\mathrm{ESBL}$ 음성, AmpC $\beta$-lactamase 양성에서 기인하는데도 Vitek2를 사용하는 기관에서 $\mathrm{ESBL}$ 양성으로 판독하여 검사 기관의 $30.0 \%$ 가 위양성으로 판독하고, cefepime MIC $\leq 1 \mu \mathrm{g} /$ $\mathrm{mL}$ 임에도 내성으로 보고하였다. Vitek 2의 expert 알고리즘 을 사용하여 감수성판독결과를 변경하는 것은 표준법은 아니 기 때문에 $\mathrm{ESBL}$ 위양성 판독 위험성에 주의해야 할 것이다. 이 균주는 amikacin, gentamicin의 일치율이 매우 낮았는데 이 균주는 $16 \mathrm{~S}$ rRNA methylase에 의한 내성기전을 가지고 있을 것으로 추정되며, 2010년 보고[10]에서 국내 임상분리 K. pneumoniae는 $16.0 \%$ 가 이 기전에 의한 내성을 가지고 있 어서 그람음성간균 중 가장 높은 빈도였고, 외국보다 훨씬 흔 하다고 발표된 바 있다. Vitek2에서 Acinetobacter baumannii 의 ArmA $16 \mathrm{~S}$ rRNA methylase에 의한 aminoglycoside 내성 
Young Jin Ko et al • Annual EQA for Clinical Microbiology 2014

Table 15. Performance of culture and identification of molds in the experimental challenge of F1401-F1405

\begin{tabular}{|c|c|c|c|}
\hline $\begin{array}{c}\text { Survey } \\
\text { no. }\end{array}$ & Expected results & $\begin{array}{c}\text { Species identification } \\
\text { results }\end{array}$ & $\begin{array}{c}\text { No. lab } \\
(\%)\end{array}$ \\
\hline \multirow[t]{12}{*}{ F1401 } & Aspergillus terreus & Aspergillus terreus & $51(56.0)$ \\
\hline & & Aspergillus sp. & $5(5.5)$ \\
\hline & & Aspergillus flavus & $3(3.3)$ \\
\hline & & Aspergillus fumigatus & $1(1.1)$ \\
\hline & & Aspergillus nidulans & $1(1.1)$ \\
\hline & & $\begin{array}{l}\text { Cryptococcus } \\
\text { laurentii }\end{array}$ & $1(1.1)$ \\
\hline & & $\begin{array}{r}\text { Mold, refer for } \\
\text { identification }\end{array}$ & $1(1.1$ \\
\hline & & Penicillium marneffei & $1(1.1)$ \\
\hline & & $\begin{array}{l}\text { Scedosporium } \\
\text { apiospermum }\end{array}$ & $3(3.3)$ \\
\hline & & Test not performed & $1(1.1)$ \\
\hline & & No response & $23(25.3)$ \\
\hline & & Total & $91(100.0)$ \\
\hline \multirow[t]{7}{*}{ F1402 } & Aspergillus fumigatus & Aspergillus fumigatus & $58(63.7)$ \\
\hline & & Aspergillus sp. & $3(3.3)$ \\
\hline & & Aspergillus nidulans & $1(1.1)$ \\
\hline & & $\begin{array}{r}\text { Mold, refer for } \\
\text { identification }\end{array}$ & $4(4.4)$ \\
\hline & & Test not performed & $1(1.1)$ \\
\hline & & No response & $24(26.4)$ \\
\hline & & Total & $91(100.0)$ \\
\hline \multirow[t]{9}{*}{ F1403 } & Aspergillus flavus & Aspergillus flavus & $50(54.9)$ \\
\hline & & Aspergillus sp. & $6(6.6)$ \\
\hline & & Aspergillus terreus & $2(2.2)$ \\
\hline & & Aspergillus niger & $1(1.1)$ \\
\hline & & Aspergillus versicolor & $1(1.1)$ \\
\hline & & $\begin{array}{r}\text { Mold, refer for } \\
\text { identification }\end{array}$ & $4(4.4)$ \\
\hline & & Test not performed & $1(1.1)$ \\
\hline & & No response & $26(28.6)$ \\
\hline & & Total & $91(100.0)$ \\
\hline \multirow[t]{5}{*}{ F1404 } & $\begin{array}{l}\text { Trichophyton } \\
\text { rubrum }\end{array}$ & Trichophyton rubrum & $42(46.2)$ \\
\hline & & Trichophyton sp. & $7(7.7)$ \\
\hline & & $\begin{array}{l}\text { Trichophyton } \\
\text { mentagrophytes }\end{array}$ & $5(5.5)$ \\
\hline & & $\begin{array}{l}\text { Trichophyton } \\
\text { tonsurans }\end{array}$ & $4(4.4)$ \\
\hline & & Aspergillus flavus & $1(1.1)$ \\
\hline
\end{tabular}

(Continued to the next page)
Table 15. Continued

\begin{tabular}{|c|c|c|c|}
\hline $\begin{array}{c}\text { Survey } \\
\text { no. }\end{array}$ & Expected results & $\begin{array}{c}\text { Species identification } \\
\text { results }\end{array}$ & $\begin{array}{c}\text { No. lab } \\
(\%)\end{array}$ \\
\hline & & Aspergillus nidulans & $1(1.1)$ \\
\hline & & Aspergillus terreus & $1(1.1)$ \\
\hline & & Coccidioides immitis & $1(1.1)$ \\
\hline & & Penicillium sp. & $1(1.1)$ \\
\hline & & Yeast like organism & $3(3.3)$ \\
\hline & & Test not performed & $1(1.1)$ \\
\hline & & No response & $25(27.5)$ \\
\hline & & Total & $91(100.0)$ \\
\hline \multirow[t]{11}{*}{ F1405 } & $\begin{array}{l}\text { Trichophyton } \\
\text { mentagrophytes }\end{array}$ & $\begin{array}{l}\text { Trichophyton } \\
\text { mentagrophytes }\end{array}$ & $30(33.0)$ \\
\hline & & Trichophyton tonsurans & $12(13.2)$ \\
\hline & & Trichophyton sp. & $9(9.9)$ \\
\hline & & Trichophyton rubrum & $8(8.8)$ \\
\hline & & Aspergillus niger & $1(1.1)$ \\
\hline & & Paecilomyces sp. & $1(1.1)$ \\
\hline & & Yeast like organism & $3(3.3)$ \\
\hline & & No growth & $1(1.1)$ \\
\hline & & Test not performed & $1(1.1)$ \\
\hline & & No response & $25(27.5)$ \\
\hline & & Total & $91(100.0)$ \\
\hline
\end{tabular}

을 놓친다는 것과 디스크확산법에서 이중 억제대를 보인다는 것이 이미 발표된 바 있다[11]. 16S rRNA methylase 내성기 전이 흔한 국내에서 16-20시간의 배양 후 MIC를 측정하는 표 준법과 달리 더 신속한 판독 알고리즘으로 감수성 검사를 하는 키트를 사용할 때 aminoglycoside 내성을 놓칠 수 있다는 것을 보여준 결과로서 임상검사실에서 감수성 검사의 질 관리에 참 고해야 할 것으로 판단하였다.

M1411 P. aeruginosa의 meropenem 감수성 결과 판정을 보류하였다. 이는 2012년 변경된 기준을 제대로 적용하지 않 았던 것과 meropenem $\mathrm{MIC}$ 가 중등도 내성범위에서 더욱 일 치율이 낮았던데 기인하여 P. aeruginosa 카바페넴 감수성판 독에 대한 질 관리의 중요함을 보여주었다.

B. cepacia, S. aureus, S. pneumoniae 항균제 감수성 검 사에서 여전히 보고할 항균제를 빠뜨리거나 잘못된 감수성 검 사법으로 검사하거나 검체에 따라 보고해서는 안 되는 항균제 를 보고하는 것 등이 부적절한 평가의 중요한 원인이었으며, vancomycin 내성 등 불가능한 내성을 보고하는 기관들도 1-2 기관 있었다. 따라서 이들 기관들은 항균제감수성 검사의 중요 
Journal of LABORATORY MEDICINE and QUALITY ASSURANCE

Young Jin Ko et al • Annual EQA for Clinical Microbiology 2014

Table 16. Performance of modified Hodge test and combined disk inhibition test of C1401, C1402, and C1403

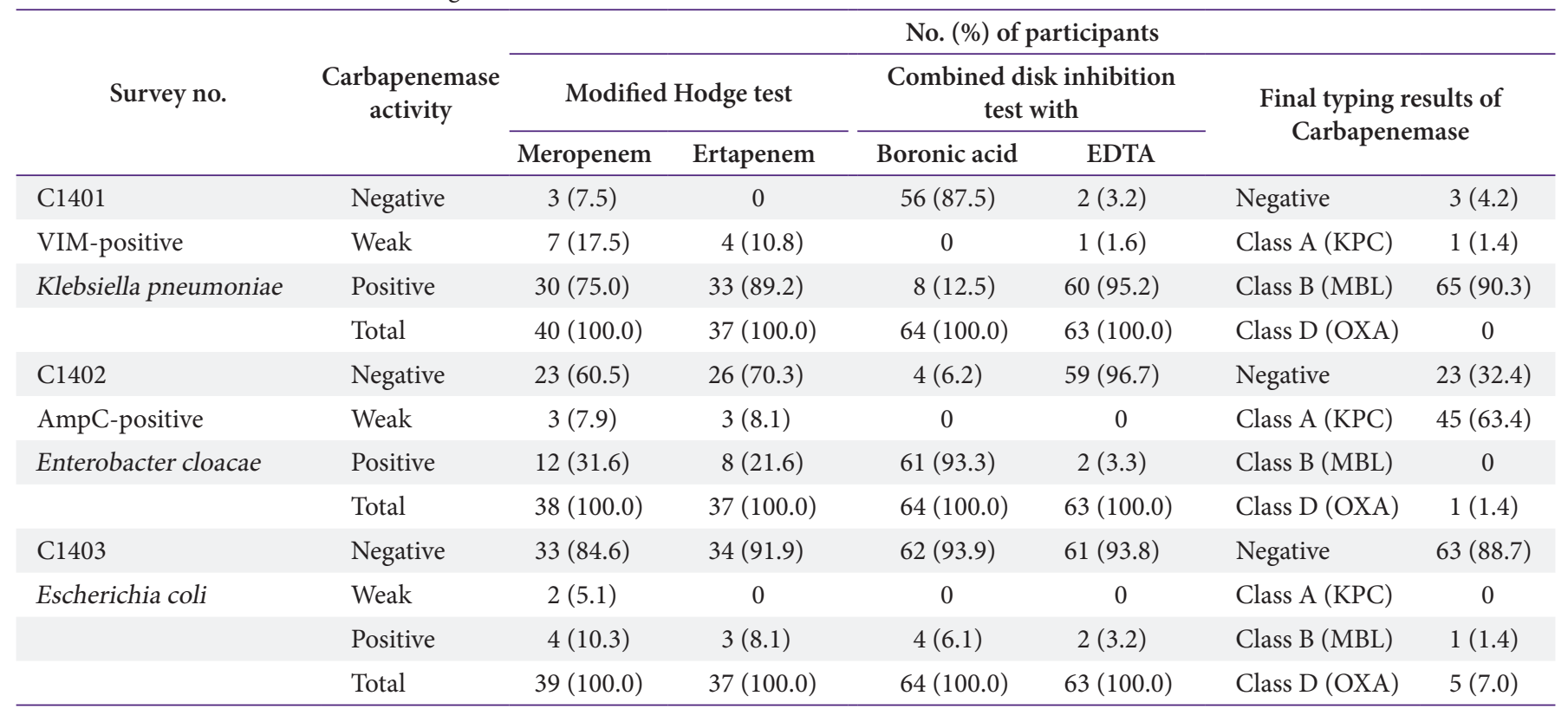

Abbreviations: KPC, Klebsiella pneumoniae carbapenemase; MBL, metallobetalactamase; OXA, Oxacillinase; Weak, weak positive.

한 질 관리방안으로 균종별 검사할 항균제 패널의 선정, 가능 성이 매우 희박한 균종항균제내성 조합 등에 대한 기준을 설 정하는 것을 우선해야 할 것이다.

M1422 Salmonella serogroup C와 Salmonella serogroup $\mathrm{D}$ 두 주 모두 fluoroquinolone 계열의 감수성 검사에 부적 합 결과가 많았다. CLSI는 장내세균속에 대한 ciprofloxacin, levofloxacin breakpoint로는 Salmonella 내성을 검출을 할 수 없기 때문에 nalidixic acid를 지시항균제로 사용할 것을 권 장해왔다. 하지만 90년대 말부터 Salmonella에서 plasmid 에 의해 확산되는 $q n r$ 유전자의 변이나 $\mathrm{aac}\left(6^{\circ}\right) \mathrm{Ib}-\mathrm{cr}$ 로 인 한 낮은 수준의 fluoroquinolone 내성이 문제가 되는데 이 들 내성은 nalidixic acid 선별만으로 검출이 어려워서[12] nalidixic acid를 지시자로 사용해도 모든 fluoroquinolone 내 성을 검출할 수는 없다고 기술하고 있다. 2012년 Salmonella 만을 위한 ciprofloxacin breakpoint를 독립적으로 만들면서 nalidixic acid를 사용하는 기관이라도 ciprofloxacin의 새로 운 breakpoint를 적용하면 추가적으로 내성을 검출하는 장점 이 있다고 권장하였고, 2014년에는 levofloxacin breakpoint가 추가되었다. 하지만 자동화된 $\mathrm{MIC}$ 검사법 장비를 주로 사용하 는 임상검사실로서 ciprofloxacin, levofloxacin 항균제의 농도 가 이 정도로 낮은 범위를 포함한 패널은 국내에 없기 때문에 nalidixic acid를 적극 활용하거나 ciprofloxacin Etest 등 보 완적인 검사방법을 마련할 필요가 있을 것이다. 이에 CLSI도
2012년에 비해 2014년 오히려 최신 breakpoint를 도입하기 전에는 nalidixic acid를 사용할 수 있다고 권장하고 있다[5].

다제내성균 감시배양에 해당하는 검체 중 M1404 MRSA 감 시배양은 비교적 높은 정답률을 보인 반면 M1413 반코마이신 감수성인 장구균과 $\mathrm{VRE}$ 를 혼합한 검체에 대해 매우 낮은 정 답률을 보였다. 이는 감시배양은 목표를 선별적으로 민감하게 키울 수 있는 선택배지를 사용해야 질을 높일 수 있음을 보여 준다.

기생충 검경은 처음 시도였는데 hookworm 충란의 동정률 이 $85.3 \%$ 로 가장 낮았고, 편충란은 $100.0 \%$ 정확도를 보였다. 가장 작은 양성 충체라고 할 수 있는 원충류인 G. intestinalis 의 동정능도 $92.2 \%$ 에 달해서 가상현미경에 의한 검경이 성공 적이었음을 보여준다. 하지만 기생충이 없는 검체에 대해 정답 률이 가장 낮았던 이유는 가상현미경상에서 1,000 배 배율까지 확대해 보지 못하는 한계점 때문일 수 있어서 향후 보완이 필 요하다.

털곰팡이류 연구모듈은 Trichophyton 종동정능이 Aspergillus보다 낮다는 것을 보여주었고, 카바페네메제 검 출검사 모듈은 $\mathrm{MHT}$ 가 $\mathrm{AmpC} \beta$-lactamase에 위양성이 있 을 수 있음을 주의해야 한다는 것을 보여 주었다. DHA-1, ACT-1, CMY-2 등은 carbapenem을 분해하는 활성도가 있 는 AmpC $\beta$-lactamase라서 위양성이 자주 발생한다[13]. 특히 국내 carbapenem 내성 장내세균은 대부분 'AmpC 


\section{Journal of LABORATORY MEDICINE and QUALITY ASSURANCE}

Young Jin Ko et al • Annual EQA for Clinical Microbiology 2014

$\beta$-lactamase+porin loss'에 기인하기 때문에 [14] MHT에 양성, boronic acid 억제 양성일 때 AmpC $\beta$-lactamase를 먼저 고려해야 한다. 국내에서 carbapenemase producing Enterobacteriacaeae 선별, 확인검사를 정착시키려면 지속적 인 교육과 질 관리가 필요할 것이다.

결론적으로 2014년 임상미생물학 신빙도조사는 항균제 내 성균 감시배양, 털곰팡이류, 기생충학 검사 등 임상미생물 분 야를 지속적으로 확대하여 참여기관에 더 포괄적인 외부정 도관리프로그램을 제공할 수 있었다. Candida 종수준 동정, Actinomyces 종의 동정, 털곰팡이류 종동정 등은 여전히 개선 이 필요한 부분이었다. 항균제 감수성의 새로운 방법 또는 기 준의 제대로 도입하지 못하거나 항균제 선정과 감수성 검사방 법을 잘못 선택하는 오류가 여전히 항균제감수성 검사에서 빈 번하여 지속적인 질 관리가 필요하였다.

\section{REFERENCES}

1. Jones RN, Glick T, Sader HS, Flamm RK, Ross JE, Rhomberg PR, et al. Educational antimicrobial susceptibility testing as a critical component of microbiology laboratory proficiency programs: American Proficiency Institute results for 2007-2011. Diagn Microbiol Infect Dis 2013;75:357-60.

2. Snell JJ, Brown DF, Perry SF, George R. Antimicrobial susceptibility testing of enterococci: results of a survey conducted by the United Kingdom National External Quality Assessment Scheme for Microbiology. J Antimicrob Chemother 1993;32:401-11.

3. Chaitram JM, Jevitt LA, Lary S, Tenover FC; WHO Antimicrobial Resistancce Group. The World Health Organization's External Quality Assurance System Proficiency Testing Program has improved the accuracy of antimicrobial susceptibility testing and reporting among participating laboratories using NCCLS methods. J Clin Microbiol 2003;41:2372-7.

4. EUCAST. Breakpoint tables for interpretation of MICs and zone diameters (http://www.eucast.org/fileadmin/ src/media/PDFs/EUCAST_files/Breakpoint_tables/ Breakpoint_table_v_4.0.pdf Accessed January 1, 2014).

5. Clinical and Laboratory Standards Institute. Performance standards for antimicrobial susceptibility testing: 24th informational supplement, M100-S24. Wayne (PA): Clinical and Laboratory Standards Institute, 2014.
6. Spellerberg B, Brandt C. Special phenotypic methods for detecting antibacterial resistance. In: Swenson JM, Patel JB, Jorgensen JH, editors. Manual of clinical microbiology. 10th ed. Washington (DC): ASM press, 2011;1168.

7. Ko YJ, Kim MN, Kim EC, Shin JH, Lee NY, Kim S, et al. Annual report on external quality assessment scheme in clinical microbiology in Korea (2013). J Lab Med Qual Assur 2014;36:122-39.

8. Kim MN, Shin JH, Sung H, Lee K, Kim EC, Ryoo N, et al. Candida haemulonii and closely related species at 5 university hospitals in Korea: identification, antifungal susceptibility, and clinical features. Clin Infect Dis 2009;48:e57-61.

9. Ng LS, Sim JH, Eng LC, Menon S, Tan TY. Comparison of phenotypic methods and matrix-assisted laser desorption ionisation time-of-flight mass spectrometry for the identification of aero-tolerant Actinomyces spp. isolated from soft-tissue infections. Eur J Clin Microbiol Infect Dis 2012;31:1749-52.

10. Lee H, Koh EM, Kim CK, Yum JH, Lee K, Chong Y. Molecular and Phenotypic Characteristics of 16S rRNA Methylase-producing Gram-negative Bacilli. Korean J Clin Microbiol 2010;13:19-26.

11. Jung S, Yu JK, Shin SH, Park KG, Jekarl DW, Han K, et al. False susceptibility to amikacin by VITEK 2 in Acinetobacter baumannii harboring armA. Ann Clin Lab Sci 2010;40:167-71.

12. Cavaco LM, Aarestrup FM. Evaluation of quinolones for use in detection of determinants of acquired quinolone resistance, including the new transmissible resistance mechanisms qnrA, qnrB, qnrS, and aac(6')Ibcr, in Escherichia coli and Salmonella enterica and determinations of wild-type distributions. J Clin Microbiol 2009;47:2751-8.

13. Mammeri H, Guillon H, Eb F, Nordmann P. Phenotypic and biochemical comparison of the carbapenemhydrolyzing activities of five plasmid-borne AmpC $\beta$-lactamases. Antimicrob Agents Chemother 2010; 54:4556-60.

14. Lee K, Lee M, Shin JH, Lee MH, Kang SH, Park AJ, et al. Prevalence of plasmid-mediated AmpC beta-lactamases in Escherichia coli and Klebsiella pneumoniae in Korea. Microb Drug Resist 2006;12:44-9. 
임상미생물학분과 신빙도조사 결과보고(2014)

고영진 ${ }^{1}$ 김미나 ${ }^{1} \cdot$ 김의종 ${ }^{2} \cdot$ 신종희 $^{3} \cdot$ 이남용 $^{4} \cdot$ 김선주 $^{5} \cdot$ 정석훈 $^{6} \cdot$ 김재석 $^{7}$ 김창기 ${ }^{8}$ - 배혜경 $\bullet$ 윤남섭 ${ }^{1}$ 주세익 ${ }^{2}$ - 황유연 ${ }^{4}$ 김건한 ${ }^{6}$ 장인호 ${ }^{10} \bullet$ 허 진 $^{11}$ 대한임상검사정도관리협회 임상미생물학분과위원회

${ }^{1}$ 울산대학교 의과대학 서울아산병원 진단검사의학과, ${ }^{2}$ 서울대학교 의과대학 서울대병원 진단검사의학과, ${ }^{3}$ 전남 대학교 의과대학 전남대병원 진단검사의학과, ${ }^{4}$ 성균관대학교 의과대학 삼성서울병원 진단검사의학과, ${ }^{5}$ 경상대 학교 의과대학 경상대병원 진단검사의학과, ${ }^{6}$ 연세대학교 의과대학 강남세브란스병원 진단검사의학과, ${ }^{7}$ 한림대 학교 의과대학 강동성심병원 진단검사의학과, ${ }^{8}$ 결핵연구원 진단검사의학과, ${ }^{9}$ 녹십자 의료재단 진단검사의학과, ${ }^{10}$ 연세대학교 원주의과대학 원주기독병원 진단검사의학과, ${ }^{11}$ 고려대학교 의과대학 안산병원 진단검사의학과

대한임상검사정도관리협회 임상미생물학분과는 2014년 3월, 6월, 9월에 신빙도조사를 하였다. 이번 신빙도조사에는 기생충학 부분이 새롭게 포함되었다. 각 조사마다 일반세균학의 그람염색, 배양, 동 정 및 감수성 검사를 위한 서로 다른 조합의 세균과 효모균 5종으로 구성된 3가지 세트와 AFB 염색 을 위한 5 개의 고정된 객담 도말 슬라이드를 배분하였다. 매 기간마다 혐기균과 털곰팡이류의 배양 및 동정을 위한 두 가지 특수세균 배양을 위한 배지를 신청기관에 분배하였고 3월과 6월 조사에는 5 개의 항산균 배양 및 동정 검체, 5 개의 항결핵제 감수성 검사를 위한 검체, 두 개의 신속 항결핵제 감 수성 검사를 위한 항산균주를 신청기관에 배분하였다. 대변 기생충 검경을 위한 5 개의 가상 현미경 슬라이드를 6월 조사 때 각 참여기관에 시험적으로 오픈하였다. 총 340 검사기관이 참여하였고 1차, 2차, 3차 조사 때 각각 330기관(97.0\%), 331기관(97.4\%), 331기관(97.4\%)이 결과를 회신하였 다. 세균동정에서는 Burkholderia cepacia, Klebsiella pneumoniae, Streptococcus pyogenes, Staphylococcus aureus, Pseudomonas aeruginosa, Streptococcus pneumoniae, Streptococcus agalactiae, Plesiomonas shigelloides, Enterococcus faecalis가 95.0\% 이상의 기관이 적절하게 답했고, M1422의 세트를 구성한 Salmonella species group C와 group D는 9 개 기관이 서로 다른 세트의 균으로 동정해 $95.0 \%$ 미만의 동정률을 보였다. 다제내성균 감시배양 중 M1404 메티실린 내성 황생포도알균과 M1413 반코마이신 내성 장구균은 각각 89.6\%와 69.0\% 의 기관만 정답을 보고하였다. Candida albicans, Candida auris, Candida glabrata, Candida parapsilosis의 동정 정확도는 각각 $86.1 \%, 1.6 \%, 48.1 \%, 83.8 \%$ 이었다. S. aureus에서 반코마이 신을 디스크확산법으로 검사하는 것과 S. pneumoniae의 페니실린 감수성 검사 누락, Salmonella 종의 퀴놀론내성을 신뢰성있게 검출할 수 있는 검사의 부재 등이 항균제 감수성 검사의 부적절한 결 과의 원인이었다. 특수세균조사에서는 털곰팡이류의 종동정에서 낮은 동정률을 보였다. 항산균 배양 동정 및 감수성 검사는 우수한 수준을 유지하였다. 대변 기생충 동정에서 연충류의 충란과 아메바 낭 은 $90.0 \%$ 이상의 적절한 동정률을 보였으나 음성 검체의 경우 $28.6 \%$ 에서 위양성 결과를 보였다. 결 론적으로, 임상미생물학에서 진균의 칸디다 종과 털곰팡이류의 종수준의 동정이 질향상이 가장 필요 한 분야였다. 또한 S. aureus에서 반코마이신 디스크확산법 검사를 하는 것과 S. pneumoniae의 페 니실린 감수성 검사 누락이 여전히 항균제감수성 검사의 부적합 결과에서 흔한 원인이었다. 기생충학 에서는 가상 현미경 검사를 성공적으로 도입하었다.

(J Lab Med Qual Assur 2015;37:153-178)

교신저자: 김미나

우)05505 서울시 송파구 올림픽로 43길 88, 서울아산병원 진단검사의학과

Tel: 02)3010-4511, Fax: 02)478-0884, E-mail: mnkim@amc.seoul.kr

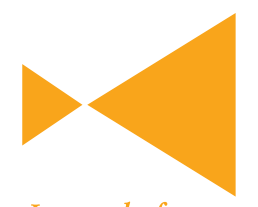

Journal of

LABORATORY MEDICINE and

QUALITY ASSURANCE 